\title{
Separate vmPFC Ensembles Control Cocaine Self-Administration Versus Extinction in Rats
}

\author{
(1)Brandon L. Warren, ${ }^{1,2}$ Louisa Kane, ${ }^{2}$ (Darco Venniro, ${ }^{2}$ Pooja Selvam, ${ }^{2}$ - Richard Quintana-Feliciano, ${ }^{1,2}$ \\ Michael P. Mendoza, ${ }^{2}{ }^{-}$Rajtarun Madangopal, ${ }^{2}$-Lauren Komer, ${ }^{2}$ Leslie R. Whitaker, ${ }^{2}$ F. Javier Rubio, ${ }^{2}$ \\ 얼ennifer M. Bossert, ${ }^{2}$ Daniele Caprioli, ${ }^{3,4}$ () Yavin Shaham, ${ }^{2}$ and ${ }^{\circ}$ Bruce T. Hope ${ }^{2}$ \\ ${ }^{1}$ Department of Pharmacodynamics, University of Florida, Gainesville Florida 32610, ${ }^{2}$ Behavioral Neuroscience Branch, Intramural Research Program, \\ National Institute on Drug Abuse-National Institutes of Health, Department of Health and Human Services, Baltimore, Maryland 21224, ${ }^{3}$ Department of \\ Physiology and Pharmacology, Sapienza University of Rome, Rome, Italy, and ${ }^{4}$ Santa Lucia Foundation (IRCCS Fondazione Santa Lucia), Rome, Italy
}

Recent studies suggest that the ventral medial prefrontal cortex (vmPFC) encodes both operant drug self-administration and extinction memories. Here, we examined whether these opposing memories are encoded by distinct neuronal ensembles within the vmPFC with different outputs to the nucleus accumbens (NAc) in male and female rats. Using cocaine self-administration ( $3 \mathrm{~h} / \mathrm{d}$ for $14 \mathrm{~d})$ and extinction procedures, we demonstrated that vmPFC was similarly activated (indexed by Fos) during cocaine-seeking tests after 0 (no-extinction) or 7 extinction sessions. Selective Daun02 lesioning of the self-administration ensemble (no-extinction) decreased cocaine seeking, whereas Daun02 lesioning of the extinction ensemble increased cocaine seeking. Retrograde tracing with fluorescent cholera toxin subunit B injected into NAc combined with Fos colabeling in vmPFC indicated that vmPFC self-administration ensembles project to NAc core while extinction ensembles project to NAc shell. Functional disconnection experiments (Daun02 lesioning of vmPFC and acute dopamine D1-receptor blockade with SCH39166 in NAc core or shell) confirm that vmPFC ensembles interact with NAc core versus shell to play dissociable roles in cocaine self-administration versus extinction, respectively. Our results demonstrate that neuronal ensembles mediating cocaine self-administration and extinction comingle in vmPFC but have distinct outputs to the NAc core and shell that promote or inhibit cocaine seeking.

Key words: Daun02 inactivation; extinction; infralimbic cortex; operant conditioning; RNAscope; vmPFC

\section{Significance Statement}

Neuronal ensembles within the vmPFC have recently been shown to play a role in self-administration and extinction of food seeking. Here, we used the Daun02 chemogenetic inactivation procedure, which allows selective inhibition of neuronal ensembles identified by the activity marker Fos, to demonstrate that different ensembles for cocaine self-administration and extinction memories coexist in the ventral $\mathrm{MPFC}$ and interact with distinct subregions of the nucleus accumbens.

\section{Introduction}

Learned associations between cues, contexts, and reward play important roles in drug addiction (Wikler, 1973; Stewart et al., 1984; Siegel, 1999). In both humans and animal models, cues and contexts present during drug taking become associated with the rewarding

\footnotetext{
Received April 23, 2019; revised July 2, 2019; accepted July 9, 2019.

Author contributions: B.L.W., M.V., L.R.W., J.M.B., D.C., Y.S., and B.T.H. designed research; B.L.W., L. Kane, M.V., P.S., R.Q.-F., M.P.M., R.M., L. Komer, L.R.W., F.J.R., J.M.B., and D.C. performed research; B.L.W., L. Kane, R.Q.-F., M.P.M., R.M., L. Komer, F.J.R., J.M.B., D.C., and B.T.H. analyzed data; B.L.W., L. Komer, B.T.H., L. Kane, M.V., R.Q.-F., R.M., L.R.W., F.J.R., J.M.B., D.C., and Y.S., wrote the paper.

This work was supported by the National Institute on Drug Abuse, Intramural Research Program, NIH, and by a Grant from the National Institute on Drug Abuse (4R00DA042102-02) to B.L.W. B.L.W. was also supported by a NARSAD Young Investigator Grant from the Brain \& Behavior Research Foundation.

The authors declare no competing financial interests.

Correspondence should be addressed to Bruce T. Hope at bhope@intra.nida.nih.gov.

https://doi.org/10.1523/JNEUROSCI.0918-19.2019

Copyright $\odot 2019$ the authors
}

effects of drugs; these cues and contexts can reactivate drug-related memories during abstinence and provoke drug craving and relapse (Wikler, 1973; O’Brien et al., 1992; Bossert et al., 2013; Venniro et al., 2016). In humans and laboratory animals, the response to drug cues can be readily extinguished by repeated exposure to the drugassociated cues in the absence of the drug reward (O'Brien et al., 1992; Conklin and Tiffany, 2002; McNally, 2014). However, extinction learning does not "erase" the original drug-taking memories because learned behaviors can recover over time (spontaneous recovery; Shaham et al., 1997) or reinstate after exposure to stress, drug-associated cues and context, or re-exposure to the drug itself (Davis and Smith, 1976; de Wit and Stewart, 1981; Crombag and Shaham, 2002). Thus, the original drug taking/seeking and extinction memories are thought to be encoded by separate neural substrates in the brain (Bouton, 2002; Khoo et al., 2017).

Inactivation of whole brain regions has identified several brain regions that separately mediate drug seeking and extinction 
(Rhodes and Killcross, 2004, 2007; Peters et al., 2008a; LaLumiere et al., 2010; Ma et al., 2014). For cocaine, projections from ventral medial prefrontal cortex (vmPFC) to nucleus accumbens (NAc) shell are thought to inhibit drug seeking after extinction, while projections from the dorsal medial PFC (dmPFC) to NAc core are thought to drive drug seeking (Peters et al., 2009). However, our studies using Daun02 inactivation do not agree with this anatomical framework and demonstrate that neuronal ensembles in vmPFC and NAc shell promote rather than inhibit heroin or cocaine seeking, respectively (Bossert et al., 2011; Cruz et al., 2014). Other studies suggest that the mPFC subregions play more complex roles in drug seeking, via the efferent projections of individual neurons (Marchant et al., 2015; Moorman et al., 2015; McGlinchey et al., 2016; Gutman et al., 2017), rather than an anatomical divide between dorsal and ventral subregions.

Operant learning involves complex associations among highly specific cues and rewards that require an encoding mechanism with a comparably high degree of resolution (Warren et al., 2017). Methods targeting all neurons within a region are not capable of this high resolution. Instead, learned associations are thought to be encoded by specific patterns of neurons, called neuronal ensembles, which are selected by cues and reinforcers during learning (Hebb, 1949). The technologies to target neuronal ensembles based on their activity have just become available (Garner et al., 2012; Cruz et al., 2013, 2015). We developed the Daun02 inactivation procedure in Fos-LacZ transgenic rats to ablate Fos-expressing ensembles that are activated during learned behaviors. The transgene transiently coexpresses $\beta$-galactosidase ( $\beta$-gal) protein with Fos in strongly activated neurons. Following intracranial injections of the inactive prodrug Daun02, the induced $\beta$-gal converts Daun02 to daunorubicin, which selectively inactivates and ablates the previously activated neuronal ensemble (Koya et al., 2009b).

Using Daun02 inactivation, we previously found that distinct neuronal ensembles within the vmPFC play a role in food selfadministration and extinction of food seeking (Warren et al., 2016). Here, we first tested whether distinct vmPFC neuronal ensembles also play a role in cocaine self-administration and extinction of cocaine seeking. We then tested whether these neuronal ensembles exert their effects on cocaine seeking through different projections to distinct NAc subregions. We used retrograde tracing with cholera toxin subunit $\mathrm{B}(\mathrm{CTb})$ to label different efferent projections from the self-administration and extinction ensembles to the NAc core and shell. Finally, we performed functional disconnection experiments with Daun02 inactivation in the vmPFC and dopamine D1 receptor (Drd1) receptor blockade of NAc core and shell subregions to confirm that although self-administration and extinction ensembles comingle in the vmPFC, their effects on cocaine seeking are controlled by different projections to the NAc.

\section{Materials and Methods}

\section{Subjects}

We used a total of 307 male Long-Evans rats (Charles River Laboratories) and Fos-lac $Z$ transgenic rats (Koya et al., 2009a), weighing between 250 and $350 \mathrm{~g}$ at the start of experiments. After surgery, we housed rats individually under a reverse $12 \mathrm{~h}$ light/dark cycle (lights off at 8:00 A.M.). Water was freely available in the rats' home cages throughout the experiment. Food was restricted to $20 \mathrm{~g}$ per day of Purina rat chow (given after the daily operant sessions). All procedures followed the guidelines outlined in the Guide for the Care and Use of Laboratory Animals (Ed 8; http://grants.nih.gov/grants/olaw/Guide-for-the-Careand-Use-of-Laboratory-Animals.pdf). From all experiments, we excluded 56 rats due to sickness, loss of patency, and for Experiments 2, 4, and 5, misplaced cannulas more rostral than $3.3 \mathrm{~mm}$ bregma or more caudal than $2.5 \mathrm{~mm}$ bregma.

\section{Surgery}

We anesthetized rats with isoflurane (5\% induction, $3 \%$ maintenance) and injected ketoprofen ( $2.5 \mathrm{mg} / \mathrm{kg}$, s.c.; Butler Schein Animal Health) daily for $2 \mathrm{~d}$ following surgery to relieve pain and decrease inflammation. We allowed the rats to recover from surgery for 3-4 $\mathrm{d}$.

\section{Intravenous catheterization surgery}

We implanted SILASTIC catheters into the jugular vein as described previously (Cruz et al., 2014; Rubio et al., 2015; Caprioli et al., 2017). We placed the distal end of the catheter into the jugular vein. We attached the proximal end of the catheter to a modified 22-gauge cannula. We ported the cannula through the midscapular region of the back. We flushed the catheters daily with gentamicin in sterile saline $(4.25 \mathrm{mg} / \mathrm{ml}$; APP Pharmaceuticals).

\section{Intracranial cannula implantation}

We implanted permanent guide cannulas (23-gauge, Plastics One) bilaterally $1 \mathrm{~mm}$ above the vmPFC. The nose bar was set at $-3.3 \mathrm{~mm}$, and the coordinates for the vmPFC were anteroposterior: +3.0 , mediolateral: \pm 1.5 , and dorsoventral: $-3.8\left(10^{\circ}\right.$ angle $)$. The coordinates for the NAc Core were anteroposterior: +1.6 , mediolateral: \pm 3.6 , and dorsoventral: $-5.9\left(20^{\circ}\right.$ angle $)$. The coordinates for the NAc Shell were anteroposterior: +1.6 , mediolateral: \pm 3.5 , and dorsoventral: $-7.0\left(20^{\circ}\right.$ angle $)$. We fixed cannulas to the rat's skull with dental cement and jeweler's screws. We used the above coordinates based on pilot and previous studies (Bossert et al., 2007, 2011, 2012; Warren et al., 2016).

\section{Intracranial injections}

We performed intracranial injections using a syringe pump (Harvard Apparatus) and $10 \mu \mathrm{l}$ Hamilton syringes that were attached via polyethylene-50 tubing to 30 -gauge injectors (Plastics One) that extended $1 \mathrm{~mm}$ beyond the guide cannula. We infused $0.5 \mu \mathrm{l}$ over $1 \mathrm{~min}$, and left the injectors in place for $1 \mathrm{~min}$ before removal.

\section{Intracranial CTb injections}

We contralaterally infused $(0.3 \mu \mathrm{l} /$ side $)$ fluorescent cholera toxin-b conjugates CTb-488 and CTb-594 (50 $\mu \mathrm{g} / \mu \mathrm{l}$; Thermo Fisher, C34775, 34777 ) into the NAc core [anteroposterior: +1.6 , mediolateral: \pm 3.6 , and dorsoventral: $-5.9\left(20^{\circ}\right.$ angle $)$ ] or shell [anteroposterior: +1.6 , mediolateral: \pm 3.5 , and dorsoventral: $-7.0\left(20^{\circ}\right.$ angle $\left.)\right]$ using a syringe pump (World Precision Instruments) and $10 \mu$ l Hamilton syringes. We infused over $2 \mathrm{~min}$, and left the injectors in place for $5 \mathrm{~min}$ before removal. We chose the concentration and volume based on previous studies (Conte et al., 2009; Jin and Maren, 2015).

\section{Drugs}

We received cocaine- $\mathrm{HCl}$ (cocaine) from the National Institute on Drug Abuse pharmacy. We chose self-administration doses of $1.0 \mathrm{mg} / \mathrm{kg} / \mathrm{infu}-$ sion and $0.5 \mathrm{mg} / \mathrm{kg} /$ infusion based on previous studies (Cruz et al., 2014). In Experiments 2, 4, and 5, on induction day, we injected Daun02 or vehicle into the vmPFC. We obtained Daun02 from Sequoia Research Products (www.seqchem.com). We dissolved Daun02 (2 $\mu \mathrm{g} / 0.5 \mu \mathrm{l} / \mathrm{side})$ in vehicle solution containing 5\% DMSO, $6 \%$ Tween 80 , and $89 \% 0.01 \mathrm{M}$ PBS. We chose the dose of Daun02 based on previous studies (Koya et al., 2009a; Bossert et al., 2011; Fanous et al., 2012; Cruz et al., 2014). In Experiments 4 and 5, we dissolve SCH39166 (SCH; Tocris Bioscience) in sterile water $(2.0 \mathrm{mg} / \mathrm{ml})$ at a dose of $1.0 \mu \mathrm{g} / 0.5 \mu \mathrm{l} / \mathrm{side}$ ( $15 \mathrm{~min}$ pretreatment time) based on our previous studies (Caprioli et al., 2017; Venniro et al., 2017).

\section{Apparatus}

We trained and tested rats in Med Associates self-administration chambers; each equipped with a retractable lever located $7 \mathrm{~cm}$ above the grid floor and a red house light. Presses on the active retractable lever activated the injection pump, a tone, and a white discrete cue-light. 
Fos immunohistochemistry

We washed coronal brain sections $(40 \mu \mathrm{m})$ in PBS, blocked with $3 \%$ normal goat serum (NGS) in PBS with $0.25 \%$ Triton X-100 (PBS-Tx), and incubated $24 \mathrm{~h}$ at $4^{\circ} \mathrm{C}$ with anti-Fos antibody (1:5000 dilution; Cell Signaling Technology, catalog \#5348; RRID:AB_10557109) in blocking solution. We then washed sections in PBS, and incubated them with biotinylated goat anti-rabbit secondary antibody (1:600 dilution; Vector Laboratories, BA-9200; RRID:AB_2336171) in PBS-Tx and 1\% NGS for $2 \mathrm{~h}$. After washing in PBS, we incubated sections for $1 \mathrm{~h}$ in avidin-biotinperoxidase complex (ABC Elite kit, PK-6100, Vector Laboratories) in PBS containing $0.5 \%$ Triton X-100. Finally, we washed sections in PBS and developed in 3,3'-diaminobenzidine (DAB) for $\sim 3 \mathrm{~min}$, washed with PBS, and mounted onto chromalum-gelatin-coated slides. Once dry, we dehydrated the slides through a graded series of alcohol $(30,60$, 90, 100, 100\% ethanol) and cleared them with Citrasolv (Fisher Scientific) before coverslipping with Permount (Sigma-Aldrich). We digitally captured bright-field images of immunoreactive (IR) cells in vmPFC using an EXi Aqua camera (QImaging) attached to a Zeiss Axioskop 2 microscope at $200 \times$ magnification (Carl Zeiss Microscopy) and iVision software for Macintosh v4.0.15 (BioVision). Observers (B.L.W., L Kane) blind to the test conditions (inter-rater reliability: Pearson's correlate $=$ 0.91) automatically counted labeled nuclei from two sections (bilateral) per rat ( 3 images per rat). We averaged the counts so that each rat was an $n$ of 1 for each brain area.

\section{Fos and NeuN immunofluorescence}

We washed coronal brain sections from Experiment $1(40 \mu \mathrm{m})$ in PBS, blocked with 3\% NGS in PBS with $0.25 \%$ Triton X-100 (PBS-Tx), and incubated $24 \mathrm{~h}$ at $4^{\circ} \mathrm{C}$ with anti-Fos antibody (1:5000 dilution; Cell Signaling Technology, catalog \#5348; RRID:AB_10557109) and NeuN antibody (1:2000; Millipore, catalog \#MAB377; RRID:AB_2298772) in blocking solution. We then washed sections in PBS, and incubated them with AlexaFluor 488-conjugated goat anti-rabbit (1:500 dilution; ThermoFisher Scientific, catalog \#A-11008; RRID:AB_143165, ) and AlexaFluor 568-conjugated anti-mouse secondary antibodies (1:500 dilution; ThermoFisher Scientific, catalog \#A-11004; RRID:AB_141371) and coverslipped with MOWIOL. We digitally captured fluorescent images of IR cells in vmPFC using a Rolera EM-C ${ }^{2}$ camera (QImaging) attached to a Nikon Eclipse E800 at 200× magnification and iVision software for Macintosh v4.0.15 (BioVision). Observers (B.L.W., L Kane) blind to the test conditions (Pearson's correlate $=0.93$ ) automatically counted labeled nuclei from two sections (bilateral) per rat (3 images per rat). We averaged the counts so that each rat was an $n$ of 1 for each brain area.

\section{RNAscope in situ hybridization assay}

For RNA in situ hybridization, we used RNAscope Multiplex Fluorescent Reagent Kit (Advanced Cell Diagnostics) according to the manufacturer's instructions and as described previously (Li et al., 2015; Rubio et al., 2015). Briefly, we fixed sections in $10 \%$ formalin at $4^{\circ} \mathrm{C}$ for $20 \mathrm{~min}$, rinsed in PBS, and dehydrated in increasing concentrations of ethanol (50, 70, $100,100 \%)$. We stored slides in $100 \%$ ethanol overnight. The next day, we dried the slides at room temperature and drew a hydrophobic barrier around the section. We then treated slides with a protease (Pretreatment 4) for $20 \mathrm{~min}$ and washed in distilled water. We then applied target probes for Fos, Slc17a7 (Vglut1, a marker of pyramidal glutamatergic projection neurons), and Slc32a1 (Vgat, a marker of GABAergic interneurons) designed by Advanced Cell Diagnostics (catalog \#403591C2, \#317001, and \#424541-C3, respectively).

We then incubated slides with a series of preamplifier and amplifier probes at $40^{\circ} \mathrm{C}$ (AMP1 for $30 \mathrm{~min}, \mathrm{AMP} 2$ for $15 \mathrm{~min}, \mathrm{AMP} 3$ for $30 \mathrm{~min}$ ). Next, we incubated slides with fluorescently labeled probes using AMP4 Alt B to detect triplex Fos (AlexaFluor 488), Vglut1 (Atto, 550), and Vgat (Atto, 647). Finally, we incubated the slides with DAPI and coverslipped them with VECTASHIELD fluorescent mounting medium (Vector Laboratories). We captured fluorescent images of labeled cells in vmPFC using a Rolera EM-C ${ }^{2}$ camera (QImaging) attached to a Nikon Eclipse E800 at $200 \times$ magnification and iVision software for Macintosh v4.0.15 (BioVision). We quantified mRNA colabeling from two hemi-sections using ImageJ ( 2 images per rat) in a blind manner.

\section{Fos immunofluorescence and CTb conjugate colabeling}

We washed coronal brain sections $(40 \mu \mathrm{m})$ in PBS, blocked with $3 \%$ NGS in PBS-Tx, and incubated $24 \mathrm{~h}$ at $4^{\circ} \mathrm{C}$ with anti-Fos antibody (1:5000 dilution; Cell Signaling Technology, catalog \#5348; RRID:AB_10557109) in blocking solution. We then washed sections in PBS, and incubated them with anti-rabbit 647 (1:500; ThermoFisher Scientific, catalog \#A32733; RRID:AB_2633282) for $3 \mathrm{~h}$. We washed sections in PBS and mounted onto chromalum-gelatin-coated slides before coverslipping with MOWIOL. We digitally captured fluorescent images of IR cells, CTb-488 and CTb-594 (50 $\mu \mathrm{g} / \mu \mathrm{l}$, ThermoFisher, C34775, C34777) in vmPFC and NAc using a Rolera EM-C ${ }^{2}$ camera (QImaging) attached to a Nikon Eclipse E800 at 200× magnification and iVision software for Macintosh v4.0.15 (BioVision). Observers (B.L.W., L Kane) blind to the test conditions (Pearson's correlate $=0.91$ automatically counted labeled nuclei from two sections (bilateral) per rat (3 images per rat). We averaged the counts so that each rat was an $n$ of 1 for each brain area. We calculated the percentage overlap between Fos-positive and CTb labeled nuclei.

\section{$X$-gal histochemistry for $\beta$-gal visualization in Fos-lacZ rats}

We used the X-gal assay based on previous studies (Koya et al., 2009a,b; Bossert et al., 2011; Warren et al., 2016). We collected coronal brain sections $(40 \mu \mathrm{m})$ of the mPFC and stored them in cryoprotectant $(20 \%$ glycerol and 2\% DMSO in $0.1 \mathrm{M} \mathrm{PBS,} \mathrm{pH} \mathrm{7.4)} \mathrm{and} \mathrm{stored} \mathrm{them} \mathrm{at}-80^{\circ} \mathrm{C}$ until use. We washed sections in PBS and incubated them in reaction buffer (0.1 M X-gal, $100 \mathrm{~mm}$ sodium phosphate, $100 \mathrm{~mm}$ sodium chloride, 5 mm EGTA, $2 \mathrm{~mm} \mathrm{MgCl}_{2}, 0.2 \%$ Triton X-100, $0.05 \mathrm{M} \mathrm{K}_{3} \mathrm{FeCN}_{6}$, and 0.05 $\mathrm{M} \mathrm{K}_{4} \mathrm{FeCN}_{6}$ ) for $2 \mathrm{~h}$ at $37^{\circ} \mathrm{C}$. We washed sections with PBS, and mounted onto chromalum-gelatin-coated slides. Once dry, we dehydrated the slides through a graded series of alcohol (30, 60, 90, 100, 100\% ethanol) and cleared them with Citrasolv (Fisher Scientific) before coverslipping with Permount (Sigma-Aldrich). We digitally captured bright-field images of reactive cells in vmPFC using an EXi Aqua camera (QImaging) attached to a Zeiss Axioskop 2 microscope at $200 \times$ magnification and iVision software for Macintosh v4.0.15 (BioVision). Observers (B.L.W., L Kane) blind to the test conditions (Pearson's correlate $=0.90$ ) automatically counted labeled nuclei from two sections (bilateral) per rat (3 images per rat). We averaged the counts so that each rat was an $n$ of 1 for each brain area.

\section{Operant conditioning and extinction of lever pressing for cocaine}

Each experiment consisted of three phases: operant cocaine selfadministration (14 d), extinction training $(0,2,7 \mathrm{~d})$, and tests for drug self-administration or extinction recall (1 d; Warren et al., 2016). During the first $7 \mathrm{~d}$ of the self-administration phase, we trained the rats to lever press to receive infusions of cocaine ( $1 \mathrm{mg} / \mathrm{kg} /$ infusion) for $3 \mathrm{~h} / \mathrm{d}$ with a maximum daily limit of 30 infusions. On Days 8-14, we halved the dose to $0.5 \mathrm{mg} / \mathrm{kg} / \mathrm{infusion}$ with a daily limit of 60 infusions. If rats reached the daily limit, the lever was retracted and the house-light turned off, signaling the end of the session. Rats earned infusions on a fixed-ratio 1 and $20 \mathrm{~s}$ timeout reinforcement schedule. During the extinction phase, responses on the previously active lever had no programmed consequences during each $3 \mathrm{~h} / \mathrm{d}$ session. During the "No Lever" period between the operant training and extinction training phases, we placed the rats in the operant conditioning chambers for $3 \mathrm{~h} / \mathrm{d}$ without the retractable lever. Finally, we tested their lever pressing under extinction conditions for $30 \mathrm{~min}$.

\section{Experimental design and statistical analysis}

Experiment 1: effect of recall of cocaine self-administration and extinction memory recall on Fos expression in vmPFC. The goal of Experiment 1 was to determine whether exposure to cues previously associated with cocaine self-administration and extinction would induce Fos expression in vmPFC. For this purpose, we first trained rats to self-administer cocaine for $14 \mathrm{~d}$. We then exposed rats in the Test groups to a short $30 \mathrm{~min}$ non-reinforced test session in which the rats lever-pressed for the cue previously associated with cocaine delivery after 0,2 , and 7 extinction sessions. We reasoned that for rats in the no Prior-extinction group $(0$ sessions) the predominant memories recalled during the 30 min test session would be the cocaine self-administration memories, whereas for rats from the other two groups ( 2 or 7 extinction sessions), the predom- 
A

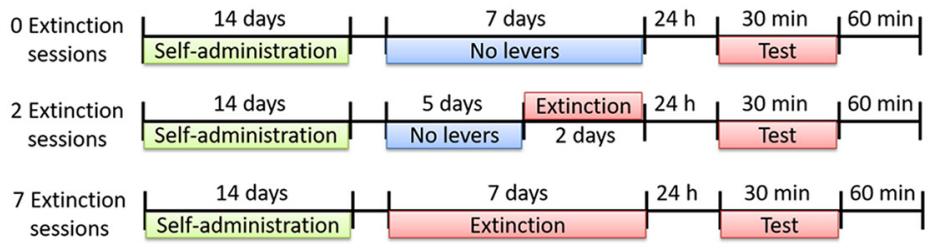

B Training and extinction

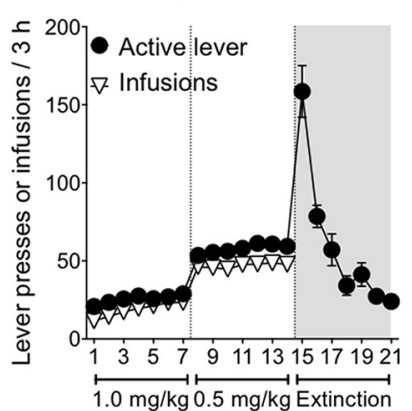

D

Fos immunoreactivity after test

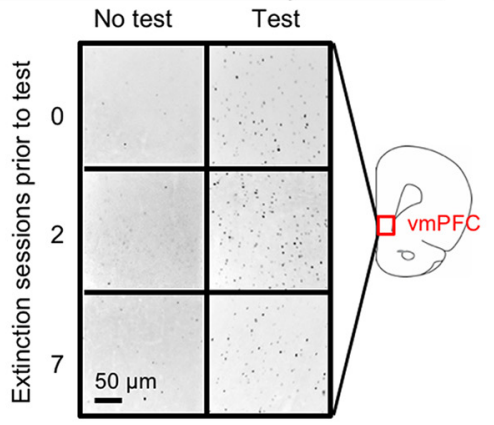

F

Fos + NeuN immunoreactivity

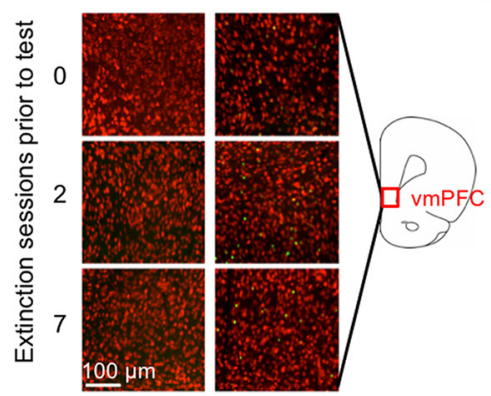

G Fos+NeuN immunoreactivity

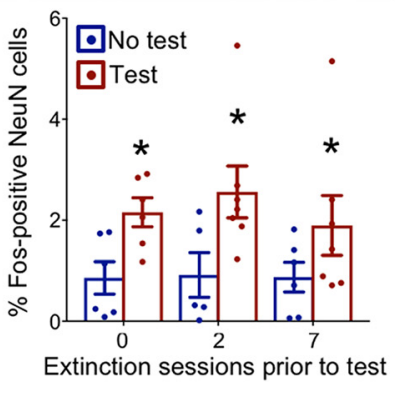

Figure 1. Experiment 1: cocaine self-administration and extinction of cocaine seeking. $\boldsymbol{A}$, Experimental timeline for extinctioninduced Fos expression. We trained rats to self-administer cocaine for $14 \mathrm{~d}$ and then divided them into three groups with different number of extinction sessions: 0,2 , or 7 sessions. No Lever indicates the sessions when we confined rats to the self-administration boxes without access to the active lever. We assessed non-reinforced cocaine seeking for $30 \mathrm{~min}$ on the recall Test day, $24 \mathrm{~h}$ after the last Extinction or No-Lever session. $\boldsymbol{B}$, Number of active lever presses and cocaine infusions earned during cocaine selfadministration and extinction training. $\boldsymbol{C}$, Number of lever presses on the active lever during the 30 min test session. Data are presented as mean \pm SEM ( $n=8-9$ per group). ${ }^{*} p<0.05$ different from 0 Extinction session group. $\boldsymbol{D}$, Representative images of Fos-IR nuclei in vmPFC captured at $200 \times$ magnification. No-Test group rats were kept in home cage. Scale bar, $50 \mu \mathrm{m}$. $\boldsymbol{E}$ Number of Fos-IR nuclei per square millimeter in vmPFC. Data are presented as mean \pm SEM ( $n=6-8$ per group). ${ }^{*} p<0.05$ different from the No-Test group for each extinction session. \#p $<0.05$ different from 0 and 7 Extinction session groups. $\boldsymbol{F}$, Representative images of merged Fos + NeuN double-labeled nuclei. All neuronal nuclei were labeled red with an antibody against the general neuronal marker NeuN. Fos-expressing nuclei were labeled green. Scale bar, $100 \mu \mathrm{m}$. G, Percentage of $($ Fos + NeuN double-labeled nuclei)/(NeuN-labeled nuclei) in vmPFC. Data are expressed as mean \pm SEM ( $n=5-7$ per group). ${ }^{*} p<0.05$ different from the No-Test group for each Extinction session.

inant memories recalled would be the extinction memories. We left the rats in the No-Test group in their home cages on test day.

We assessed Fos expression in the vmPFC in 44 rats using a $3 \times 2$ between-subjects factorial experimental design: Prior-extinction ses- sions $(0,2,7$ sessions $) \times$ Test $($ No-Test, Test). The experimental timeline is shown in Figure $1 A$. We trained rats for $14 \mathrm{~d}$ to lever press for cocaine infusions as described above. We divided these rats into three groups that received 0,2 , or 7 Prior-extinction sessions with all groups previously matched based on lever pressing during the last day of self-administration training. We exposed rats in the $0 \mathrm{~d}$ extinction group to seven daily of No-Lever sessions. Rats in the $2 \mathrm{~d}$ extinction group underwent five daily No-Lever sessions, followed by two daily extinction-training sessions. Rats in the $7 \mathrm{~d}$ extinction group underwent seven daily $3 \mathrm{~h}$ extinction-training sessions. The use of variable No-Lever sessions was to ensure that each group of rats was time-matched at the time of testing and had equal handling and exposure to the chambers. On test day, $24 \mathrm{~h}$ after the last extinction or No-Lever session, we divided each group of rats again into two groups that we placed into the test chamber under non-reinforced conditions for $30 \mathrm{~min}$ (Test) or left in their home cages (No-Test). In accordance with the Fos time course, 90 min after the start of the test session, we anesthetized rats with isoflurane for $90 \mathrm{~s}$ and perfused them with $100 \mathrm{ml}$ of PBS, followed by $400 \mathrm{ml}$ of $4 \%$ paraformaldehyde in $0.1 \mathrm{~m}$ PBS. We postfixed the brains for an additional $90 \mathrm{~min}$ in paraformaldehyde and incubated them in 30\% sucrose in PBS at $4^{\circ} \mathrm{C}$ for $2-3 \mathrm{~d}$. We froze brains in powdered dry ice and kept them at $-80^{\circ} \mathrm{C}$ until sectioning. We used these brains for Fos immunohistochemistry, as described in the Fos and NeuN Immunofluorescence section.

We repeated Experiment 1 in a separate set of rats $(n=32)$ to determine the cellular phenotype of the Fos expressing neurons using the same $3 \times 2$ factorial experimental design with Prior-extinction sessions $(0,2,7) \times$ Test $(\mathrm{No}-$ Test, Test). We killed these rats $30 \mathrm{~min}$ after the beginning of the test session, froze their brains for $20 \mathrm{~s}$ in $-40^{\circ} \mathrm{C}$ isopentane and stored the brains at $-80^{\circ} \mathrm{C}$ until use. We collected coronal brain sections $(16 \mu \mathrm{m})$ directly onto Super Frost Plus slides (Fisher Scientific) and stored them at $-80^{\circ} \mathrm{C}$ until use. We used these sections for RNAscope analysis, as described above.

Experiment 2: effect of Daun02 inactivation of neurons in vmPFC activated during recall of cocaine self-administration or extinction memories. We used the Daun02 inactivation procedure (Koya et al., 2009a; Bossert et al., 2011; Cruz et al., 2014) to determine whether distinct Fos-expressing neuronal ensembles in vmPFC play a causal role in the recall of extinction memories. The experimental procedure was similar to that of Experiment 1, with the exception that added a short 30 min "induction" session, identical to the subsequent test session, to recall the putative cocaine self-administration or extinction memories. We hypothesized that extinction memories are recalled during induction day in rats that previously experienced 2 or $7 \mathrm{~d}$ of extinction training. Therefore, we predicted that post-session injections of Daun02 would inactivate ensembles encoding extinction memories and impair extinction recall in the subsequent test session $2 \mathrm{~d}$ 
later, resulting in increased cocaine seeking. Conversely, to the degree that Daun02 inactivation on induction day would inactivate cocaine self-administration memories in the 0 extinction sessions group, this would lead to decreased cocaine seeking on the subsequent test for cocaine seeking $2 \mathrm{~d}$ later.

We examined Fos-lac $Z$ rats $(n=67)$ using $3 \times 2$ between-subjects factorial experimental design: Prior-extinction sessions $(0,2,7 \mathrm{~d}) \times$ Injection (vehicle, Daun02). The experimental timeline is shown in Figure $3 A$. We anesthetized Fos-lacZ rats (previously bred for 45-50 generations on a Sprague-Dawley background) and implanted permanent guide cannulas bilaterally into their vmPFC as described above. After a minimum of $7 \mathrm{~d}$ recovery, we trained rats using the same procedure described in Experiment 1 . After training the rats to leverpress for cocaine for $14 \mathrm{~d}$, we divided them into three groups that received 0, 2, or seven Priorextinction sessions with both groups previously matched based on lever pressing from the last day of self-administration training. The rats then underwent either $7 \mathrm{~d}$ of extinction (7 d group) $5 \mathrm{~d}$ of No Lever, followed by two extinction sessions ( $2 \mathrm{~d}$ group), or $7 \mathrm{~d}$ of No Lever ( $0 \mathrm{~d}$ group $)$. On induction day, $24 \mathrm{~h}$ later, we placed the rats into the test chamber under extinction conditions for $30 \mathrm{~min}$ to induce $\beta$-gal protein expression. We then returned rats to their home cages, and $90 \mathrm{~min}$ after the start of the induction session, we injected vehicle or Daun02 into the vmPFC as described. Two days later, we tested all rats for non-reinforced lever presses during a brief $30 \mathrm{~min}$ recall test. Following this test, we returned all rats to their home cages. Ninety minutes after the start of the session, we deeply anesthetized the rats with isoflurane and perfused them with PBS and $4 \%$ PFA. We removed their brains and processed them for X-gal staining, as described in the ' $\mathrm{X}$-gal histochemistry for -gal visualization in Fos-lacZ rats' section.

Experiment 3: activation of $v m P F C$ to NAc projections during cocaine self-administration and extinction recall. The goal of Experiment 3 was to determine whether neuronal ensembles associated with cocaine self-administration or extinction preferentially project to different NAc subregions. We hypothesized that neuronal ensembles associated with self-administration of cocaine project to the core, whereas those associated with extinction project to the shell (Peters et al., 2008a, 2009). We used an experimental procedure similar to Experiment 1 , except that $24 \mathrm{~h}$ after the last cocaine self-administration session, we contralaterally infused $\mathrm{CTb}$ conjugates (CTb488 and CTb594) into the core and shell $(n=21)$. We then subjected the rats to either 0 or $7 \mathrm{~d}$ of extinction sessions as described. Based on the results of Experiment 2, we did not include a $2 \mathrm{~d}$ of extinction group. Twenty-four hours after the last extinction or No-Lever session, we placed rats into the test chambers for a $30 \mathrm{~min}$ test of recall under extinction conditions to induce Fos. Ninety minutes after the start of the session, we deeply anesthetized the rats with isoflurane and perfused them with PBS and 4\% PFA. We removed their brains and processed them for immunofluorescence staining, as described in the Fos immunofluorescence and CTb conjugate colabeling section.

Experiment 4: disconnection of vmPFC neuronal ensembles to shell and core during recall of extinction memories. To test whether an interaction of activated vmPFC ensembles to shell are necessary for extinction of co- caine seeking, we performed a disconnection experiment using Fos-LacZ transgenic rats $(n=26)$. This experiment is a variation of an anatomical asymmetric disconnection procedure. In classical asymmetric disconnection procedure, unilateral manipulations are performed either in the same hemisphere (unilateral) or in opposite hemispheres (contralateral). The role of the pathway is inferred when behavior is disrupted by the contralateral, but not ipsilateral manipulation. Here, we injected Daun02 unilaterally into the vmPFC on induction day to inactivate neuronal ensembles associated with extinction of cocaine seeking, and then $2 \mathrm{~d}$ later on test day, we injected the Drd1 antagonist SCH at a dose of 1.0 $\mu \mathrm{g} / 0.5 \mu \mathrm{l} /$ side into the contralateral or ipsilateral shell of the same rats to inhibit neurons that would normally be activated during reactivation of the extinction memory. We used $\mathrm{SCH}$, because blockade of Drd1 decreases NAc Fos expression induced by exposure to drug-associated cues and contexts (Ciccocioppo et al., 2001; Hamlin et al., 2007). The experiment was a single-factor between-subjects design with three groups: No-Daun02, ipsilateral, or contralateral. The No-Daun02 control received a vehicle injection into vmPFC on induction day and a unilateral $\mathrm{SCH}$ injection on test day. The experimental timeline is shown in Figure 
$5 A$. We trained rats to self-administer cocaine as described in Experiments 1-2 and extinguished the lever pressing for $7 \mathrm{~d}$. On induction day, $24 \mathrm{~h}$ after the last extinction session, we exposed the rats to a brief ( 30 min) session of extinction recall. We waited 90 min for Fos and $\beta$-gal expression, and then infused either vehicle or Daun02 unilaterally into the vmPFC to inactivate neuronal ensembles associated with extinction recall. Two days later on test day, we infused $\mathrm{SCH}$ either ipsilaterally or contralaterally into the NAc shell to inhibit local neural activity. We then waited $10 \mathrm{~min}$ after $\mathrm{SCH}$ infusions before initiating a $30 \mathrm{~min}$ test of extinction recall.

We also performed an identical experiment targeting extinctionassociated ensembles projecting to the NAc core to test whether activated projections from vmPFC to core are necessary for extinction of cocaine seeking using Fos-LacZ transgenic rats $(n=24)$. The goal of this anatomical control experiment was to rule out that the effect of $\mathrm{SCH}$ infusions into the shell was due to diffusion to the nearby core.

Experiment 5: disconnection of vmPFC neuronal ensembles to core during recall of cocaine self-administration memories. To test whether an interaction of activated vmPFC ensembles to core are necessary for recall of the memories of cocaine self-administration, we performed a disconnection experiment using Fos-LacZ transgenic rats $(n=37)$. This experiment is identical to Experiment 4 except that we performed the disconnection between vmPFC neuronal ensembles and NAc core in rats that did not undergo extinction training. The experiment was a single factor betweensubjects design with three groups: No-Daun02, ipsilateral, or contralateral. The No-Daun02 control received a vehicle injection into vmPFC on induction day and a unilateral SCH injection into the core on test day. The experimental timeline is shown in Figure 6A. We trained rats to self-administer cocaine as described in Experiments 1-4. On induction day, 1 week after the last training session, we exposed the rats to a brief (30 min) session of cocaine seeking recall. We waited $90 \mathrm{~min}$ for Fos and $\beta$-gal expression, and then infused either vehicle or Daun02 unilaterally into the vmPFC (counterbalanced across left and right hemispheres) to inactivate neuronal ensembles associated with cocaine self-administration. Two days later on test day, we infused $\mathrm{SCH}$ either ipsilaterally or contralaterally into the NAc core to inhibit neurons that would normally be activated during reactivation of the cocaine self-administration memory. We then waited $10 \mathrm{~min}$ after $\mathrm{SCH}$ infusions before initiating a 30 min test of cocaine seeking.

\section{Statistical analysis}

We analyzed the behavioral and immunohistochemical data in Experiments 1 and 2 by one-way and two-way ANOVAs using Prism (GraphPad Software). For test-day behavior following Daun02 in Experiment 2, we used a two-way ANCOVA with active lever pressing on induction day as the covariate. For these experiments, we used Holm-Sidak for post hoc analyses when the prior $\mathrm{AN}(\mathrm{C}) \mathrm{OVAs}$ indicated significant main or interaction effects $(p<0.05)$. For the CTb tracing experiment in Experiment 3 , we analyzed test-day lever presses with an unpaired $t$ test. For the disconnection experiments in Experiments 4 and 5, we analyzed test-day lever presses by one-way ANOVAs. We used Dunnett's test for post hoc analysis when the ANOVA indicated significant main or interaction effects $(p<0.05)$.

\section{Results}

For all experiments in our study, we hypothesized that the cocaine "self-administration" memory was recalled on Test day following 0 Prior-extinction sessions, whereas the "extinction" memory was recalled on Test day following 2 and 7 Prior-extinction sessions.

\section{Experiment 1: effect of recall of cocaine self-administration memories and extinction memories on Fos expression in vmPFC}

The design of Experiment 1 is shown in Figure $1 A$. Figure $1 B$ shows the mean \pm SEM number of infusions earned and active lever presses during the self-administration and extinction phases. We performed two separate one-way ANOVAs with repeated measures to assess lever pressing across self-administration sessions and across extinction sessions. The rats learned to lever press for cocaine during the self-administration phase $\left(F_{(13,520)}=56.6, p<0.0001\right)$ and decreased lever pressing when infusions were withheld during the extinction phase $\left(F_{(6,78)}=28.5, p<0.0001\right)$. These were the "Priorextinction sessions" before test day.

On recall test day, non-reinforced lever pressing was assessed for $30 \mathrm{~min}$ (Fig. 1C). One-way ANOVA indicated a significant effect of Prior-extinction sessions $\left(F_{(2,23)}=21.2, p<0.0001\right)$. Post hoc analysis indicated that either two or seven Prior-extinction sessions reduced active lever pressing on test day compared with rats that received zero extinction sessions $(p<0.0001)$.

We analyzed Fos protein expression in the vmPFC following the test recall sessions; sample images from vmPFC are shown in Figure $1 D$. Two-way ANOVA indicated a significant main effect of Test day exposure (No-Test, Test; $F_{(1,34)}=34.42, p<0.0001$ ), but not Prior-extinction sessions $\left(F_{(2,34)}=2.9, p=0.067\right)$, and a significant interaction between the two factors $\left(F_{(2,34)}=3.7, p=\right.$ 0.034). Post hoc analysis indicated that Fos expression was increased in Test rats compared with No-Test controls after 0 ( $p=$ $0.047), 2(p<0.0001)$, and $7(p=0.047)$ days of extinction (Fig. $1 E)$. Subsequent double labeling for Fos and the general neuronal marker NeuN (Fig. $1 F$ ) indicated that Fos was expressed at a basal range of $0.7-0.8 \%$ and an induced range of $2-2.5 \%$ of neurons in vmPFC (Fig. $1 G$ ). Two-way ANOVA indicated a significant main effect of Test-day exposure (No-Test, Test; $F_{(1,31)}=13.02, p=$ $0.0011)$, but not Prior-extinction sessions $\left(F_{(2,31)}=0.32, p=\right.$ $0.73)$, and no significant interaction between the two factors $\left(F_{(2,31)}=0.24, p=0.79\right)$.

To determine the phenotype of Fos-expressing neurons in the vmPFC, we used in situ hybridization to label Fos, Slc17a7 (Vglut1), and Slc32a1 (Vgat) mRNA in a separate set of rats trained identically to the first experiment. Vglut1 is a marker of glutamatergic pyramidal neurons in PFC (Bellocchio et al., 2000; Geisler et al., 2007), whereas Vgat is a marker of GABAergic interneurons (Meister, 2007). Sample images from vmPFC are shown in Figure $2 A$. Figure $2 B$ shows Fos mRNA expression patterns 30 min after the start of the test. Two-way ANOVA indicated a significant main effect of Test-day exposure $\left(F_{(1,26)}=\right.$ $51.4, p<0.0001)$, but not Prior-extinction sessions $\left(F_{(2,26)}=0.2\right.$, $p>0.05)$ and no significant interaction between the two factors $\left(F_{(2,26)}=0.1, p>0.05\right)$. Approximately $90 \%$ of Fos-expressing neurons colabeled with Vglut1 (Fig. 2C), whereas $<10 \%$ colabeled with $\operatorname{Vgat}$ (Fig. 2D). The percentages of each cell type within the Fos-expressing ensembles were not significantly different among rats tested after 0,2 , or 7 previous days of extinction.

\section{Experiment 2: effect of Daun02 inactivation of neurons in vmPFC activated during recall of cocaine self-administration or extinction memories}

We used the Daun02 inactivation procedure (Koya et al., 2009a; Bossert et al., 2011; Cruz et al., 2014) to determine whether distinct Fos-expressing neuronal ensembles in vmPFC play a causal role in the recall of cocaine self-administration and extinction memories. For this purpose, we added a short 30 min induction session, identical to the subsequent test session $2 \mathrm{~d}$ later, to first recall the putative cocaine self-administration memories or extinction memories and then inactivate these memories using post-session Daun02 injections. We tested the hypothesis that inactivating extinction and cocaine self-administration memories during induction day would lead to increases and decreases in cocaine seeking during the test day, respectively.

The design of Experiment 2 is shown in Figure $3 A$. Figure $3 B$ shows the mean \pm SEM number of infusions earned and active 
A Timeline for Daun02 inactivation experiment
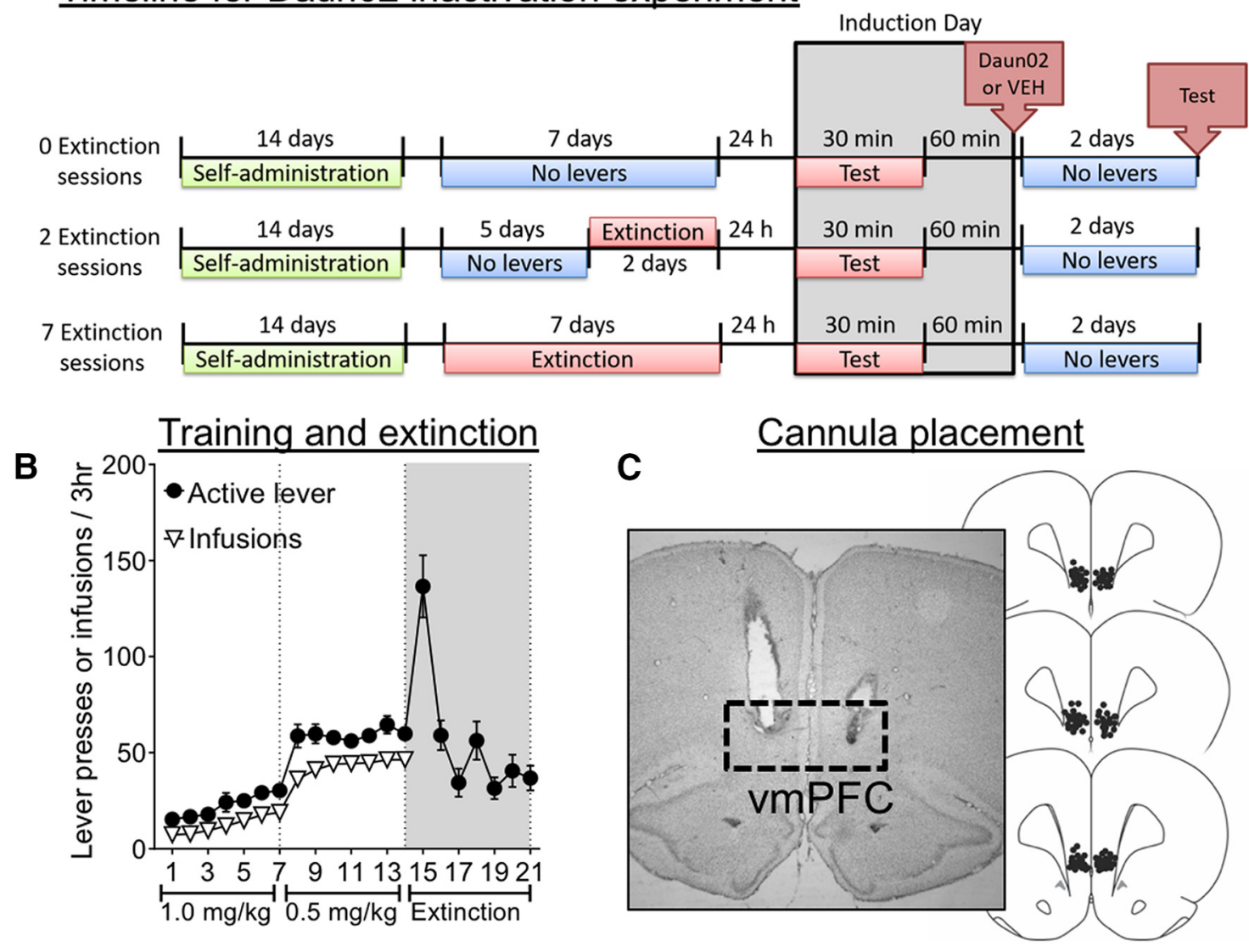

D

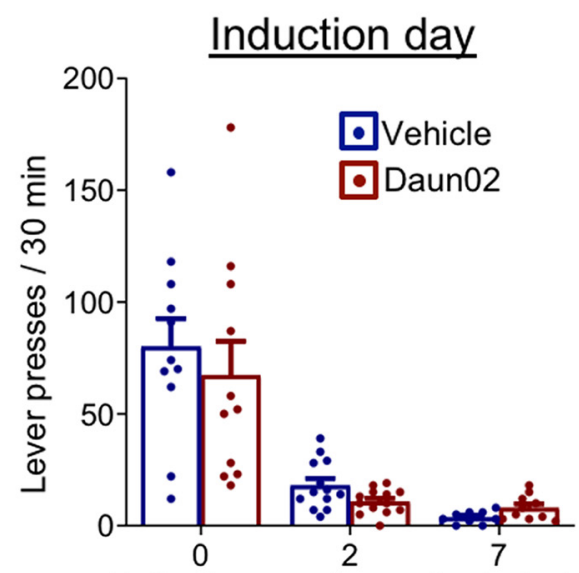

Extinction sessions prior to test
$\mathbf{E}$

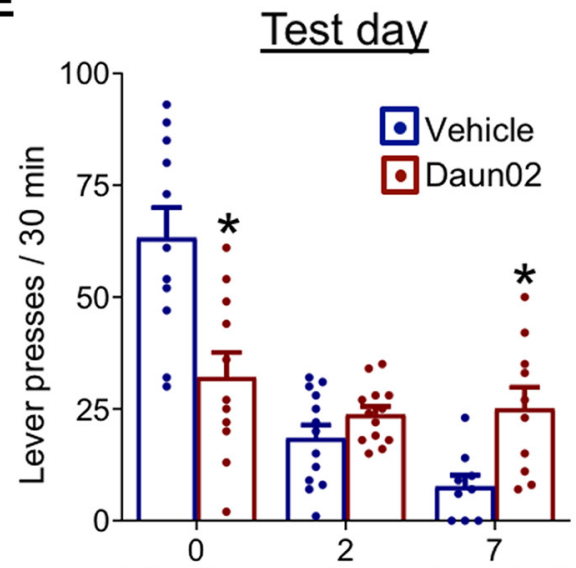

Extinction sessions prior to test

Figure 3. Experiment 2: Daun02 inactivation of activated vmPFC neurons during recall of cocaine self-administration or extinction of cocaine seeking. $\boldsymbol{A}$, Experimental timeline for the Daun02 inactivation experiment. We trained rats to self-administer cocaine for $14 \mathrm{~d}$. We divided them into three groups with varying number of extinction sessions: 0,2, or 7 sessions. 0 induction day, we gave the rats a 30 min non-reinforced induction session before injecting them bilaterally with Daun02 or vehicle (VEH) 60 min later. On recall test day, $3 \mathrm{~d}$ later, we assessed cocaine seeking under extinction conditions. $\boldsymbol{B}$, Number of active lever presses and cocaine infusions earned during self-administration and extinction training. $\boldsymbol{C}$, Images showing placement of cannulas into vmPFC. $\boldsymbol{D}$, Number of active lever presses over a $30 \mathrm{~min}$ session on induction day before Daun02 injections. $\boldsymbol{E}$, Number of active lever presses over a 30 min extinction session on test day. Data are presented as mean \pm SEM ( $n=9-13$ per group). ${ }^{*} p<0.05$ different from vehicle.

lever presses during the self-administration and extinction training phases. We performed two separate one-way ANOVAs with repeated measures to assess lever pressing across selfadministration sessions and across extinction sessions. The rats learned to lever press for cocaine during the self-administration phase $\left(F_{(13,572)}=42.2, p<0.0001\right)$ and decreased lever pressing when cocaine rewards were removed during the extinction phase
$\left(F_{(6,114)}=11.4, p<0.0001\right)$. Figure $3 C$ shows cannula placement for these rats.

On induction day, non-reinforced lever pressing was assessed for $30 \mathrm{~min}$ before being placed in their home cages for $60 \mathrm{~min}$ and injected with Daun02 or vehicle into the vmPFC (Fig. $3 D$ ). We hypothesized that the cocaine self-administration memory is recalled following zero extinction sessions, while the extinction 
memory is recalled following seven Prior-extinction sessions. The rats that have not experienced extinction maintain the leverreward association from self-administration, whereas the rats that have experienced extinction are likely to recall the extinction memory during testing. On test day, we assessed the behavioral effects of prior Daun02 inactivation of the putative cocaine selfadministration and extinction-associated neuronal ensembles (Fig. 3E).

Two-way ANOVA of induction-day lever presses before Daun02 injections indicated a significant main effect of Priorextinction sessions $\left(F_{(2,61)}=40.4, p<0.0001\right)$, but no difference between the injection groups that would later receive Daun02 or vehicle $\left(F_{(2,61)}=0.62, p=0.43\right)$, nor a significant interaction between the two main factors $\left(F_{(2,61)}=0.53, p=0.59\right)$. Post hoc analysis indicated the rats that received two and seven Priorextinction sessions pressed the active lever less than rats that received zero extinction sessions $(p<0.0001)$, respectively.

We performed a two-way repeated measures ANCOVA of test day lever presses to determine whether Daun02 infusions influenced lever presses on test day across Drug (Daun02 or Vehicle) and Prior-extinction (0, 2, or 7 Prior-extinction sessions). We used lever pressing on induction day as the covariate to account for individual differences in non-reinforced lever pressing.

The two-way ANCOVA indicated no significant main effects of Daun02 injections $\left(F_{(1,60)}=1.7, p=0.679\right)$ or Priorextinction sessions $\left(F_{(2,60)}=2.2, p=0.124\right)$, but there was a significant interaction between the two factors $\left(F_{(2,60)}=19.7, p<\right.$ $0.001)$. Post hoc analysis indicated that Daun02 injections reduced active lever presses $\sim 50 \%$ in rats with 0 Prior-extinction sessions $(p=0.006)$, but increased lever presses more than threefold in rats that underwent 7 Prior-extinction sessions compared with vehicle-treated controls $(p=0.007)$. Following testing, we perfused rats and assessed $\beta$-gal expression in vmPFC. Two-way ANOVA indicated that $\beta$-gal expression did not vary as a function of the number of Prior-extinction sessions $\left(F_{(2,49)}=2.1, p=\right.$ $0.13)$, Daun02 injection $\left(F_{(2,49)}=0.01, p=0.99\right)$, nor was there a significant interaction between the two factors $\left(F_{(1,49)}=0.17, p=\right.$ $0.68)$. In Vehicle-treated rats, 0 Prior-extinction sessions induced $373 \pm 104 \beta$-gal-positive nuclei/ $\mathrm{mm}^{2}, 2$ Prior-extinction sessions induced $442 \pm 68 \beta$-gal-positive nuclei $/ \mathrm{mm}^{2}$, and 7 Priorextinction sessions induced $251 \pm 68 \beta$-gal-positive nuclei $/ \mathrm{mm}^{2}$. In Daun02-treated rats, 0 Prior-extinction sessions induced $395 \pm 103 \beta$-gal-positive nuclei/ $\mathrm{mm}^{2}, 2$ Prior-extinction sessions induced $466 \pm 100 \beta$-gal-positive nuclei $/ \mathrm{mm}^{2}$, and 7 Priorextinction sessions induced $296 \pm 60 \beta$-gal-positive nuclei $/ \mathrm{mm}^{2}$.

Because Daun02 interacts exclusively with $\beta$-gal in Fosexpressing ensembles (Cruz et al., 2013), the results of bidirectional modulation of cocaine seeking after Daun02 injections suggest that distinct neuronal ensembles within the vmPFC encode cocaine self-administration and extinction memories.

\section{Experiment 3: neuronal ensembles associated with cocaine self-administration or extinction project to different NAc subregions}

To determine whether Fos-expressing self-administration or extinction ensembles in the vmPFC project preferentially to different NAc subregions, we used retrograde CTb conjugates to label these projections.

Figure $4 A$ shows CTb infusion placements in the NAc core and shell subregions. CTb spread for shell injections were limited to the medial shell (but not to the dorsal horn), whereas CTb spread for core injections were limited to the dorsomedial core. Figure $4 B$ shows representative $\mathrm{CTb}$ and Fos labeling in the
vmPFC following recall of the Extinction or Self-administration memories. Figure $4 C$ shows the number of neurons within the vmPFC showing CTb labeling from the Core. Two-way ANOVA indicates no significant main effect of Test-day exposure $\left(F_{(1,17)}\right.$ $=0.005, p=0.94)$, Prior-extinction sessions $\left(F_{(1,17)}=0.005, p=\right.$ $0.94)$ and no significant interaction between the two factors $\left(F_{(1,17)}=0.95, p=0.34\right)$. Figure $4 D$ shows the number of neurons within the vmPFC expressing CTb labeling from the Shell. Two-way ANOVA indicates no significant main effect of Testday exposure $\left(F_{(1,17)}=0.12, p=0.73\right)$ or Prior-extinction sessions $\left(F_{(1,18)}=0.46, p=0.51\right)$ with no significant interaction between the two factors $\left(F_{(1,17)}=3.8, p=0.08\right)$.

Figure $4 E$ shows Fos immunoreactivity 90 min after the start of the test. Two-way ANOVA indicates a significant main effect of Test-day exposure $\left(F_{(1,17)}=18.36, p=0.0005\right)$, but not of Priorextinction sessions $\left(F_{(1,17)}=0.02, p=0.88\right)$ and no significant interaction between the two factors $\left(F_{(1,17)}=0.65, p=0.43\right)$. Post hoc analysis indicated that Test-day exposure increased Fos expression in both the $0(p=0.029)$ and $7(p=0.036)$ Prior days of extinction groups compared with No-Test controls. In Figure $4 F$, we compared percentage of Fos-positive cells in the vmPFC that projected to either NAc shell or NAc core. Two-way ANOVA indicated no significant main effects of projection (core, shell; $\left.F_{(1,18)}=0.04, p=0.85\right)$ or Prior-extinction sessions $\left(F_{(1,18)}=\right.$ $0.3, p=0.59)$, but there was a significant interaction between the two factors $\left(F_{(1,18)}=14.0, p=0.001\right)$. Post hoc analyses indicated that Fos-expressing neurons associated with $7 \mathrm{~d}$ of extinction had significantly less colabeling with CTb coming from the NAc core $(p=0.03)$, but significantly more colabeling with CTb coming from the NAc shell $(p=0.01)$ compared with rats in the $0 \mathrm{~d}$ of extinction group.

Together, the results of Experiments 1-3 suggest that the vmPFC is activated by recall of both self-administration and extinction memories. Furthermore, neuronal ensembles associated with recall of cocaine self-administration preferentially project to NAc core, whereas ensembles associated with recall of extinction of cocaine seeking preferentially project to NAc shell.

\section{Experiment 4: effect of disconnecting activated vmPFC ensembles to NAc shell on extinction of cocaine seeking}

The goal of Experiment 4 was to determine whether neuronal ensemble-specific interactions with the NAc shell, indirectly or directly, are necessary for extinction of cocaine seeking. Combined with the Daun02 inactivation results of Experiment 2, we hypothesized that the vmPFC neurons that are activated by extinction of cocaine seeking inhibit cocaine seeking through projections to the shell. From this, we predicted that contralateral inactivation of extinction-associated ensembles in vmPFC with Daun02 and ensemble nonspecific inhibition of NAc shell neurons with $\mathrm{SCH}$ would increase lever pressing relative to the ipsilateral manipulation; this was the key comparison. The ipsilateral manipulation preserves one functional hemisphere to mediate behavior, whereas the contralateral manipulation interferes with the function of both hemispheres in behavior. We chose the Drd1 antagonist SCH to inhibit neurons in the NAc shell or core subregions because we wanted to independently confirm our $\mathrm{CTb}$ findings about whether the vmPFC ensembles have separate interactions with the different NAc subregions. The No-Daun02 control groups received vehicle infusions into the vmPFC and $\mathrm{SCH}$ injections into the NAc shell or core. The No-Daun02 control was used only to compare with the ipsilateral test group to assess whether unilateral injections of Daun02 have an effect on behavior. 
A $\underline{\text { CTb injections }}$

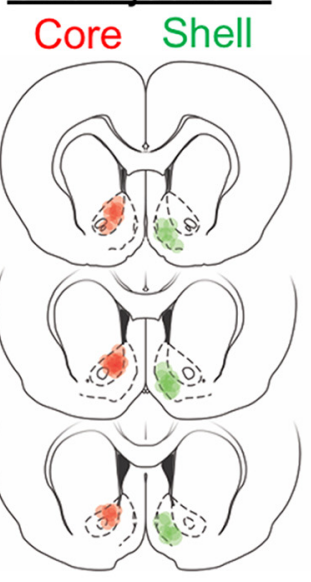

B $\quad$ vmPFC neurons projecting

to Core to Shell

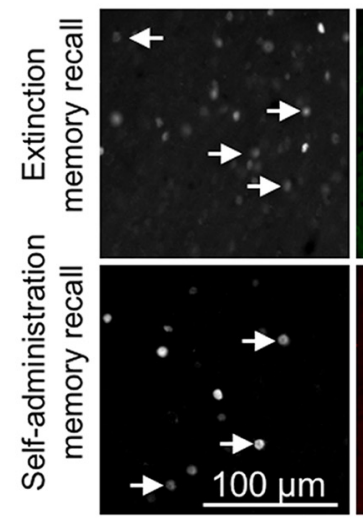

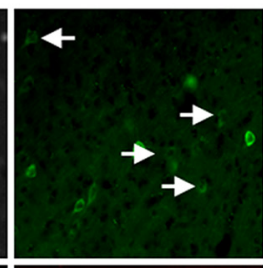
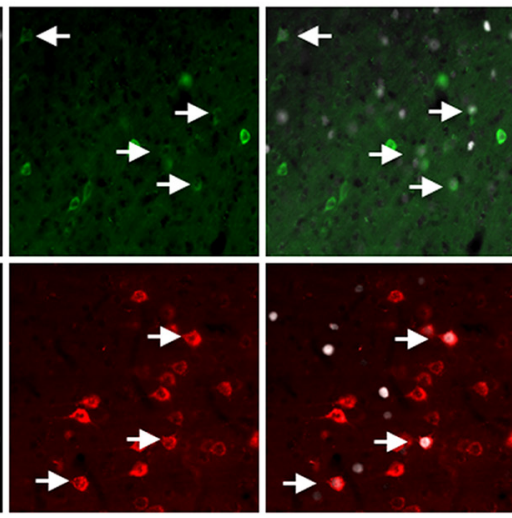

C vmPFC-Core CTb labeling

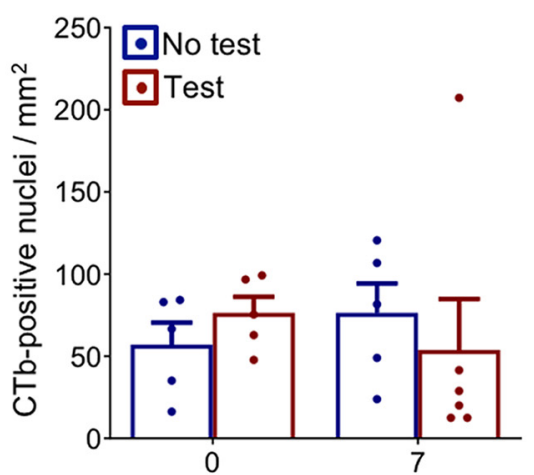

Extinction sessions prior to test
D vmPFC-Shell CTb labeling

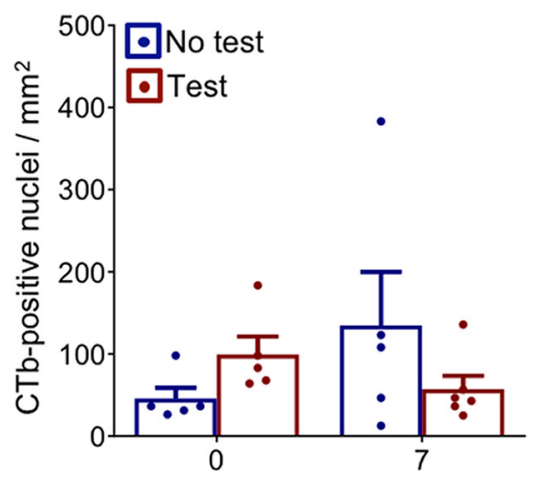

Extinction sessions prior to test

\section{E Fos expression: vmPFC}

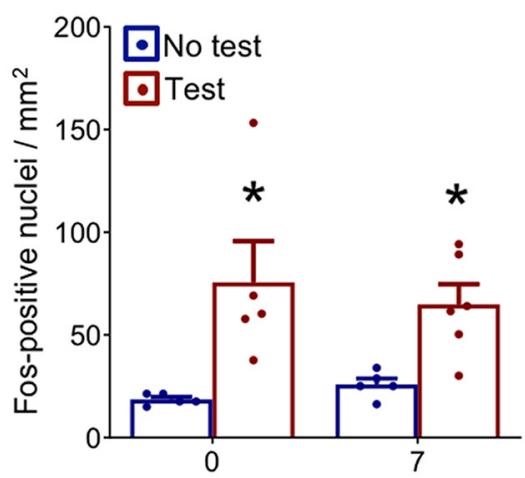

Extinction sessions prior to test

F $\quad \underline{C T b+F o s ~ c o-l a b e l i n g: ~ v m P F C ~}$

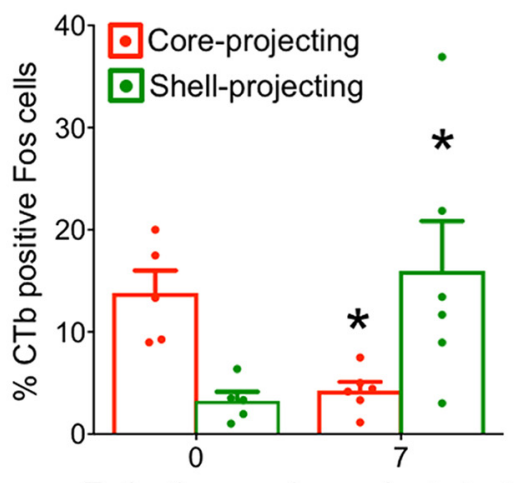

Extinction sessions prior to test

Figure 4. Experiment $3: \mathrm{VmPFC}$ neuronal ensembles associated with cocaine self-administration or extinction recall project to different subregions of the NAc. $A$, Placement of CTb infusions into nucleus accumbens. $\boldsymbol{B}$, Representative images showing (Tb-AlexaFluor 594 or (Tb-AlexaFluor 488 colabeling with Fos expression in the vmPFC of rats that underwent 0 (Self-administration) or 7 (Extinction) Prior-extinction sessions. Core-projecting neurons are labeled red, whereas shell-projecting neurons are labeled green; the white arrows indicate neurons double-labeled for CTb and Fos. C, Number of core CTb-labeled nuclei per square millimeter in vmPFC. D, Number of shell CTb-labeled nuclei per square millimeter in vmPFC. $E$, Number of Fos-labeled nuclei per mm ${ }^{2}$ in vmPFC. ${ }^{*} p<0.05$ different from the No-Test group for each extinction session. $\boldsymbol{F}$, Percentage of CTb-labeled cells that colabel with Fos in the vmPFC. Data are presented as mean \pm SEM $(n=5-6$ per group). ${ }^{*} p<0.05$ different from corresponding projection group in 0 Extinction session group.

The timeline of Experiment 4 is shown in Figure 5A. We performed two separate one-way ANOVAs with repeated measures to assess lever pressing across self-administration sessions and across extinction sessions. The rats learned to lever press for infusions of cocaine during the self-administration phase $\left(F_{(13,390)}=18.2, p<\right.$ 0.0001 ) and decreased their lever presses during the $7 \mathrm{~d}$ of extinction training $\left(F_{(6,168)}=17.7, p<0.0001 ;\right.$ Fig. $\left.5 B\right)$. Cannula placements in vmPFC and NAc Shell are shown in Figure $5 C$.

On Test day, we assessed the behavioral effects of inactivating extinction-associated neuronal ensembles in vmPFC with ipsilateral or contralateral inactivation of the shell. All rats received $\mathrm{SCH}$ injections into the NAc Shell. One-way ANOVA indicated 


\section{Pharmacological disconnection experiment vmPFC->shell (and core control)}

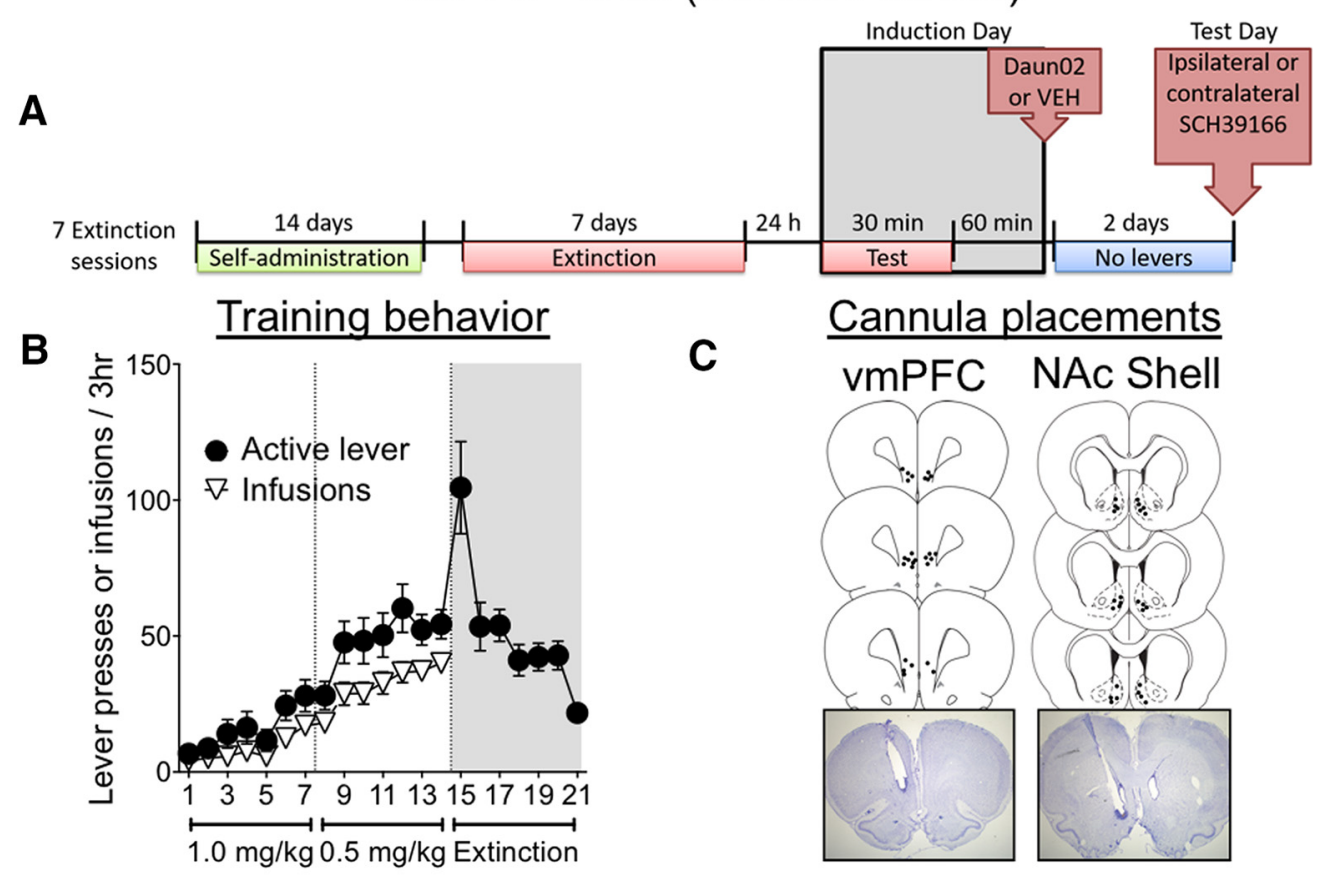

\section{Pharmacological disconnection - Test day lever pressing}

D

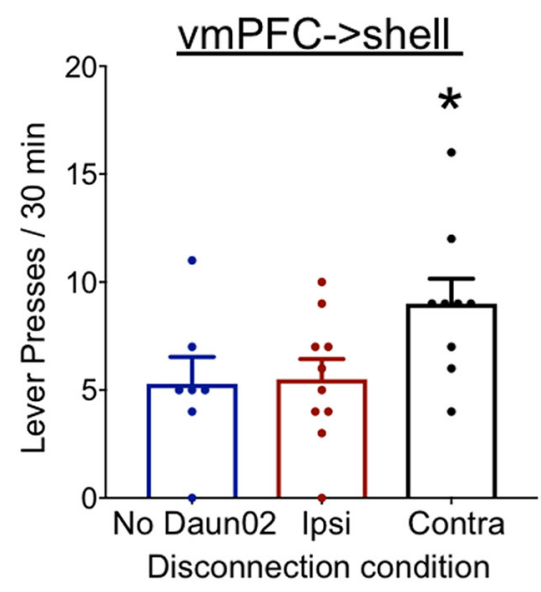

E

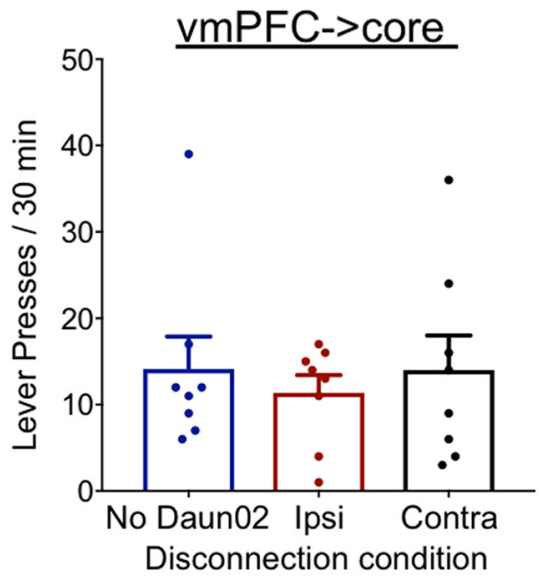

Figure 5. Experiment 4: Pharmacological disconnection of vmPFC neuronal ensembles and NAc shell and core during recall of extinction of cocaine seeking. $A$, We trained rats to self-administer cocaine for $14 \mathrm{~d}$ and subsequently exposed them to 7 extinction sessions. On induction day, we exposed them to a 30 min non-reinforced recall session and infused Daun 02 or vehicle (VEH) into one hemisphere of the vmPFC 90 min after the start of the session. Two days later, on Test day, we infused SCH (10 min pretreatment time) into the ipsilateral or contralateral NAc shell and tested for extinction memory recall during a non-reinforced 30 min test session. $\boldsymbol{B}$, Number of active lever presses and cocaine infusions earned during self-administration and extinction. $\boldsymbol{C}$, Images showing placement of cannulas into vmPFC (left) and NAc shell (right). $\boldsymbol{D}$, Number of active lever presses during the 30 min non-reinforced test session after unilateral SCH injections into the NAC shell. Data are presented as mean \pm SEM ( $n=7-10$ per group). $\boldsymbol{E}$, Number of active lever presses during the 30 min non-reinforced test session after unilateral SCH injections into the NAc core. Data are presented as mean $\pm \operatorname{SEM}\left(n=8\right.$ per group). ${ }^{*} p<0.05$ different from ipsilateral group.

that active lever presses varied as a function of the Group condition $\left(F_{(2,23)}=3.6, p=0.04\right)$. Post hoc analysis using Dunnett's test indicated that contralateral Daun $02+\mathrm{SCH}$ injections increased active lever presses compared with ipsilateral injections $(p=0.0505$; Fig. 5D). Lever pressing in the No-Daun02 control was not significantly different from the ipsilateral test group $(p=$ $0.987)$. These data suggest that extinction-associated neuronal ensembles within vmPFC play a role in cocaine seeking via interactions with the NAc shell. The behavioral effect is specific to vmPFC-shell interactions, because a similar experiment targeting extinction-ensemble projections to NAc core found no effect $\left(F_{(2,21)}=0.21, p=0.81\right.$ for a main effect of Group; Fig. $\left.5 E\right)$.

Together, the results of Experiment 4 suggest that vmPFC neuronal ensembles that interact with the NAc Shell play a role in inhibition of lever pressing after extinction.

Experiment 5: disconnection of activated vmPFC ensembles to NAc core on cocaine seeking before extinction

The goal of Experiment 5 was to determine whether neuronal ensemble-specific interactions with the NAc core, directly or in- 


\section{Pharmacological disconnection experiment}

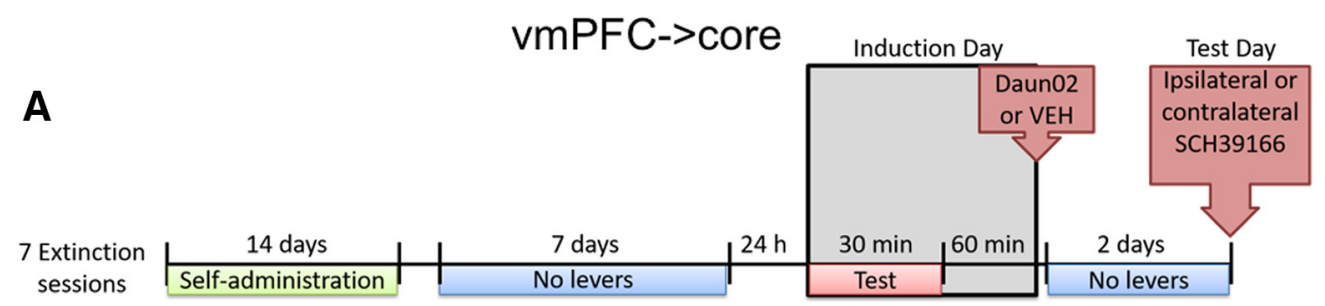

B

Training behavior

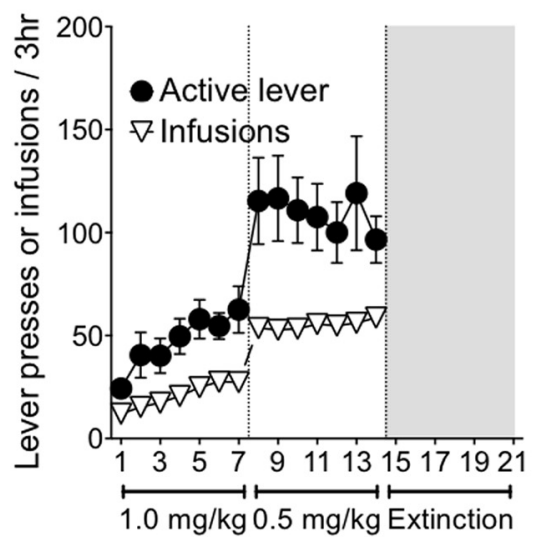

C Cannula placements vmPFC NAc Core
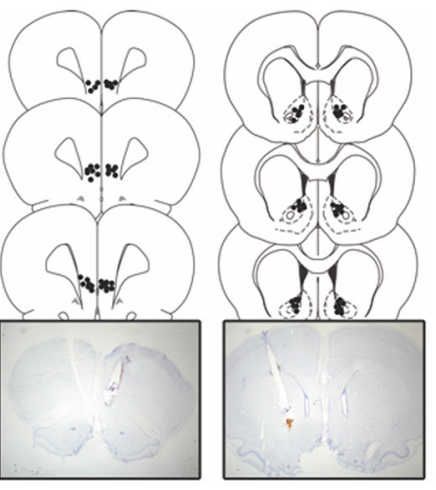

D Pharmacological disconnection - test day lever pressing

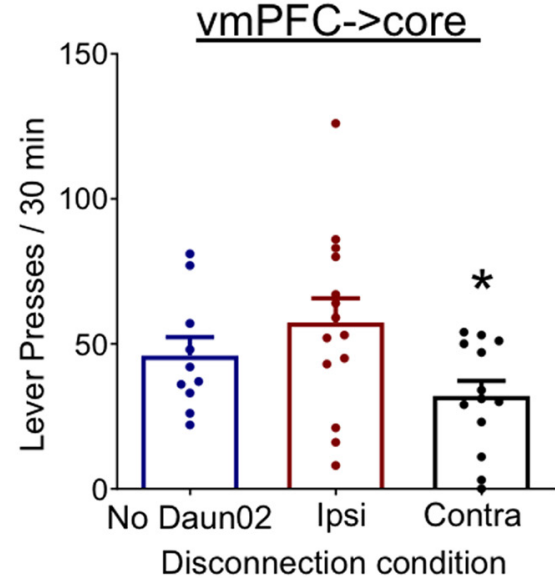

Figure 6. Experiment 5: Pharmacological disconnection of vmPFC neuronal ensembles and NAc core during recall of cocaine self-administration. $A$, We trained rats to self-administer cocaine for $14 \mathrm{~d}$ followed by seven No-Lever sessions in the chamber. On induction day, we exposed them to a 30 min non-reinforced recall test session and infused Daun02 or vehicle (VEH) into the vmPFC of one hemisphere $90 \mathrm{~min}$ after the start of the session. Two days later, on Test day, we infused SCH into the NAc core of the ipsilateral or contralateral hemisphere and tested self-administration memory recall during a non-reinforced $30 \mathrm{~min}$ test session. We infused SCH-39166 unilaterally in all rats, either ipsilaterally or contralaterally to prior vehicle or Daun02 injections into the vmPFC. $B$, Number of active lever presses and cocaine infusions earned during self-administration. C, Images showing placement of cannulas into vmPFC (left) and NAc core (right). D, Number of active lever presses during the 30 min non-reinforced test session after unilateral SCH injections into the NAc shell. Data are presented as mean \pm SEM $\left(n=10-14\right.$ per group). ${ }^{*} p<0.05$ different from ipsilateral.

directly, are necessary for cocaine seeking before extinction. Based on the results of Experiments 2 and 3, we hypothesized that cocaine self-administration-encoding vmPFC ensembles drive cocaine seeking through projections to the core. From this, we predicted that contralateral inactivation of self-administrationassociated ensembles in vmPFC with Daun02 and ensemble nonspecific inhibition of NAc core with SCH would decrease lever pressing relative to ipsilateral inactivation; this was the key comparison. The No-Daun02 control groups received vehicle infusions into the vmPFC and $\mathrm{SCH}$ injections into the NAc core. The
No-Daun02 control was used only to compare with the ipsilateral test group to assess whether unilateral injections of Daun02 and SCH have an effect on behavior.

The timeline of Experiment 5 is shown in Figure 6A. We performed two separate one-way ANOVAs with repeated measures to assess lever pressing across self-administration sessions and across extinction sessions. The rats learned to lever press for infusions of cocaine during the self-administration phase $\left(F_{(13,468)}\right.$ $=11.4, p<0.0001$; Fig. $6 B$ ). Cannula placements in vmPFC and NAc core are shown in Figure $6 C$. 
On test day, we assessed the behavioral effects of inactivating cocaine-associated neuronal ensembles in vmPFC with ipsilateral or contralateral inactivation of the core. One-way ANOVA indicated that active lever presses varied as a function of the Group condition $\left(F_{(2,35)}=3.6, p=0.04\right)$. Post hoc analysis using Dunnett's test indicated that contralateral Daun02 $+\mathrm{SCH}$ injections decreased active lever presses compared with ipsilateral Daun02 $+\mathrm{SCH}$ injections $(p=0.022$; Fig. $6 D)$. Lever pressing in the No-Daun 2 control was not significantly different from the ipsilateral test group $(p=0.603)$. Together, the results of Experiment 5 suggest that vmPFC neuronal ensembles interact with the NAc core to drive cocaine seeking.

\section{Discussion}

We found that separate neuronal ensembles in vmPFC contribute to recall of cocaine self-administration and extinction memories. Self-administration and extinction recall induced similar levels of Fos expression in similar proportions of glutamate and GABAergic neurons in vmPFC. Fos-expressing neurons in the self-administration ensemble projected preferentially to the NAc core, whereas Fos-expressing neurons in the extinction ensemble projected preferentially to the NAc shell. Daun02 ablation of the self-administration ensemble (0 Prior-extinction sessions) reduced lever pressing in a test for cocaine seeking, whereas Daun02 ablation of the extinction ensemble (7 Prior-extinction sessions) increased lever pressing in the same test. Subsequent anatomical disconnection experiments indicated that the selfadministration ensemble drives cocaine seeking via interactions with the NAc core, whereas the extinction ensemble inhibits cocaine seeking via interactions with the NAc shell. These data indicate that self-administration and extinction memories can be encoded within neuronal ensembles that intermingle within the same brain area but exert their behavioral effects through distinct outputs to different downstream brain regions.

\section{Role of vmPFC in drug and non-drug reward seeking}

The mPFC plays a critical role in learning and memory for both drug and natural rewards (Kalivas and Volkow, 2005; Phillips et al., 2008; Floresco, 2013). It has been hypothesized that the mPFC mediates reward seeking and inhibition of reward seeking after extinction via distinct subregions: the dmPFC drives reward seeking, whereas the vmPFC inhibits reward seeking (Peters et al., 2008b, 2009; Peters and De Vries, 2013). Inactivation experiments seem to support this hypothesis. Pharmacological or optogenetic inhibition of the dmPFC decreases food and drug seeking after extinction (McFarland and Kalivas, 2001; Capriles et al., 2003; Nair et al., 2011; Stefanik et al., 2013). Conversely, lesions or inactivation of vmPFC induce reinstatement and potentiate spontaneous recovery of drug or food rewards (Rhodes and Killcross, 2004, 2007; Peters et al., 2009). However, results from other studies (Jonkman et al., 2009; Koya et al., 2009b; Bossert et al., 2011, 2012; Moorman et al., 2015; McGlinchey et al., 2016), do not support the hypothesis that dmPFC and vmPFC have opposing roles in reward seeking.

We used the Daun02 inactivation procedure to selectively inactivate neuronal ensembles previously activated by recall of cocaine self-administration memories or extinction memories. Inactivation of neurons associated with recall of cocaine selfadministration memories decreased lever pressing in a subsequent test for cocaine seeking. This finding is consistent with our previous findings showing that inactivation of neuronal ensembles associated with food or drug-paired cues and contexts decreased food or drug seeking, respectively (Bossert et al., 2011;
Cruz et al., 2014; Warren et al., 2016; Caprioli et al., 2017). Conversely, we showed that inactivation of neurons previously activated by recall of extinction of cocaine seeking increased lever pressing in the subsequent cocaine-seeking test. This finding is also consistent with our previous findings using food as a reward (Warren et al., 2016), suggesting that neuronal ensembles in vmPFC also mediate extinction learning. This finding adds to a growing literature suggesting that neuronal ensembles within vmPFC are capable of encoding different and even opposing learned behaviors (Suto et al., 2016; Warren et al., 2016). Further research would be necessary to determine whether similar selfadministration and extinction ensembles were used for both food and cocaine seeking. It is possible that some Daun02 may have diffused to the dmPFC region; however, this does not affect the hypothesis that different intermingling ensembles contribute to self-administration versus extinction.

Our findings with Daun02 inactivation bring up an interesting question about the recall of self-administration versus extinction memories. The same set of cues and conditions are present during recall of both memories. However, it appears that the most recent operant learning experience with these cues determines which of these memories and their associated neuronal ensembles are activated. If the last lever pressing experience was with cocaine, then the self-administration memory and associated ensemble was recalled. If the last lever pressing experience was without reinforcer, then the extinction memory and associated ensemble was recalled. An interesting possibility is that activation of the extinction ensemble inhibits the self-administration ensemble, and that Daun02 ablation of the extinction ensembles removes inhibition of the self-administration ensemble. We speculate that the lack of behavioral effect after Daun02 ablation of neuronal ensembles following two Prior-extinction sessions was because at this time point, the same cues activated both selfadministration and extinction memories and associated ensembles. However, the extinction ensemble was not fully formed after just $2 \mathrm{~d}$ of extinction and had not yet developed enough to repress the self-administration ensemble.

The composition of the current Fos-expressing neuronal ensembles is consistent with previous findings (Bossert et al., 2011; Fanous et al., 2012; Cruz et al., 2013, 2014, 2015). Only a small percentage $(\sim 2 \%)$ of neurons in vmPFC of our 2-dimensional histochemical slices were Fos-positive. This translates $\sim$ to $0.3 \%$ in a 3 -dimensional volume, which is the more realistic percentage of neurons within these ensembles. Fos neurons are sparsely distributed and rarely in clusters. Thus, Fos-expressing ensembles cannot be considered merely smaller homotypic divisions, especially since these ensembles intermingle in the same brain area. Consistent with previous findings, we found that both pyramidal glutamatergic projection neurons and GABAergic neurons were activated during the test sessions using in situ hybridization. Ninety percent of the Fos-expressing neurons in vmPFC were Vglut1 (glutamatergic) cells. Less than 10\% of Fos-expressing neurons were GABAergic ( $V g a t)$. No differences in cell type were seen between activated neurons after 0,2 , or 7 Prior-extinction sessions. Therefore, comparable proportions of projection and interneurons are activated by the recall of cocaine selfadministration memories and extinction memories. Because recall of cocaine self-administration and extinction of cocaine seeking involve heterogeneous populations of cells, this finding emphasizes that specific memories are encoded by precise patterns of neuronal activation that are generally cell-type independent (Bossert et al., 2011; Fanous et al., 2012; Cruz et al., 2014; Li et al., 2015; Rubio et al., 2015; Caprioli et al., 2017). These results 
also emphasize that brain region or cell-type-specific manipulations do not mimic or model endogenous activity in learned behaviors.

Role of vmPFC outputs to NAc core and shell in drug seeking We found that distinct neuronal ensembles for self-administration and extinction preferentially project to different NAc subregions. The self-administration ensemble preferentially projects to the NAc core, while the extinction ensemble preferentially projects to the NAc shell. These separate projections support the hypothesis that these two ensembles are largely non-overlapping and physically distinct from each other. Furthermore, when we contralaterally inactivated neuronal ensembles associated with recall of the extinction memory, lever pressing increased compared with ipsilateral controls. Conversely, when we inactivated neuronal ensembles associated with recall of the self-administration memory, lever pressing decreased compared with ipsilateral controls. These findings suggest that the self-administration and extinction ensembles exert their effects on behavior through distinct downstream connections.

An issue to consider, however, is that the results from our anatomical disconnection experiments showed relatively small effects. These relatively small effects may be due to projections coming from the still intact contralateral vmPFC extinction ensembles that may convey extinction-related information (James et al., 2018). These results mirror findings from chemogenetic activation studies suggesting opposing roles of the mPFC to NAc core and shell pathways in driving and inhibiting drug seeking after extinction (Augur et al., 2016), as well as supporting earlier studies showing that NAc neuronal ensembles mediate drugrelated learning (Koya et al., 2009a; Cruz et al., 2014). On the other hand, McGlinchey et al. (2016) did not find that activated Fos-expressing vmPFC neurons project preferentially to NAc core versus shell during tests of reinstatement or extinction recall. The critical difference here may be that McGlinchey et al. (2016) used DAB amplification to identify Fos-expressing neurons, while we used immunofluorescence. DAB amplification is more sensitive than immunofluorescence and the latter method may have lowered the detection threshold to include weakly activated neurons, while the higher detection threshold with immunofluorescence likely identified only the most strongly activated neurons. It is possible that the additional neurons detected in the McGlinchey et al. (2016) study masked the subpopulation of neurons identified here.

An important consideration is that our vmPFC ensemble neurons are primarily glutamatergic pyramidal neurons with efferents to many brain areas in addition to the NAc (Chang et al., 1997; Marchant et al., 2016; Venniro et al., 2017; Bloodgood et al., 2018). The retrograde transport of CTb detects only the direct projections from vmPFC to NAc and does not assess the alternative efferents from the vmPFC ensemble neurons. In addition, the anatomical disconnection strategy does not require a direct monosynaptic projection from vmPFC to NAc to be effective. Thus, it is possible that the vmPFC ensembles control selfadministration and extinction behaviors via indirect projections from vmPFC to NAc rather than via direct projections from the vmPFC ensembles to the NAc.

\section{Concluding remarks}

In conclusion, we showed causal roles for intermingling neuronal ensembles in vmPFC that contribute to self-administration and extinction of cocaine seeking through distinct interactions with
NAc core and shell. Our experiments support the hypothesis that neuronal ensembles mediating opposing behaviors can coexist and compete within one brain area. More generally, these data emphasize that when studying the neural circuitry of learned behaviors, we have to consider that the nodes of communication are not necessarily brain areas or cell types but likely intermingling neuronal ensembles made up of small numbers of sparsely distributed neurons of heterogeneous cell types.

\section{References}

Augur IF, Wyckoff AR, Aston-Jones G, Kalivas PW, Peters J (2016) Chemogenetic activation of an extinction neural circuit reduces cue-induced reinstatement of cocaine seeking. J Neurosci 36:10174-10180.

Bellocchio EE, Reimer RJ, Fremeau RT Jr, Edwards RH (2000) Uptake of glutamate into synaptic vesicles by an inorganic phosphate transporter. Science 289:957-960.

Bloodgood DW, Sugam JA, Holmes A, Kash TL (2018) Fear extinction requires infralimbic cortex projections to the basolateral amygdala. Transl Psychiatry 8:60.

Bossert JM, Poles GC, Wihbey KA, Koya E, Shaham Y (2007) Differential effects of blockade of dopamine D1-family receptors in nucleus accumbens core or shell on reinstatement of heroin seeking induced by contextual and discrete cues. J Neurosci 27:12655-12663.

Bossert JM, Stern AL, Theberge FR, Cifani C, Koya E, Hope BT, Shaham Y (2011) Ventral medial prefrontal cortex neuronal ensembles mediate context-induced relapse to heroin. Nat Neurosci 14:420-422.

Bossert JM, Stern AL, Theberge FR, Marchant NJ, Wang HL, Morales M, Shaham Y (2012) Role of projections from ventral medial prefrontal cortex to nucleus accumbens shell in context-induced reinstatement of heroin seeking. J Neurosci 32:4982-4991.

Bossert JM, Marchant NJ, Calu DJ, Shaham Y (2013) The reinstatement model of drug relapse: recent neurobiological findings, emerging research topics, and translational research. Psychopharmacology 229:453-476.

Bouton ME (2002) Context, ambiguity, and unlearning: sources of relapse after behavioral extinction. Biol Psychiatry 52:976-986.

Capriles N, Rodaros D, Sorge RE, Stewart J (2003) A role for the prefrontal cortex in stress- and cocaine-induced reinstatement of cocaine seeking in rats. Psychopharmacology 168:66-74.

Caprioli D, Venniro M, Zhang M, Bossert JM, Warren BL, Hope BT, Shaham Y (2017) Role of dorsomedial striatum neuronal ensembles in incubation of methamphetamine craving after voluntary abstinence. J Neurosci 37:1014-1027.

Chang JY, Sawyer SF, Paris JM, Kirillov A, Woodward DJ (1997) Single neuronal responses in medial prefrontal cortex during cocaine selfadministration in freely moving rats. Synapse 26:22-35.

Ciccocioppo R, Sanna PP, Weiss F (2001) Cocaine-predictive stimulus induces drug-seeking behavior and neural activation in limbic brain regions after multiple months of abstinence: reversal by $\mathrm{D}_{1}$ antagonists. Proc Natl Acad Sci U S A 98:1976-1981.

Conklin CA, Tiffany ST (2002) Applying extinction research and theory to cue-exposure addiction treatments. Addiction 97:155-167.

Conte WL, Kamishina H, Reep RL (2009) Multiple neuroanatomical tracttracing using fluorescent alexa fluor conjugates of cholera toxin subunit $B$ in rats. Nat Protoc 4:1157-1166.

Crombag HS, Shaham Y (2002) Renewal of drug seeking by contextual cues after prolonged extinction in rats. Behav Neurosci 116:169-173.

Cruz FC, Koya E, Guez-Barber DH, Bossert JM, Lupica CR, Shaham Y, Hope BT (2013) New technologies for examining the role of neuronal ensembles in drug addiction and fear. Nat Rev Neurosci 14:743-754.

Cruz FC, Babin KR, Leao RM, Goldart EM, Bossert JM, Shaham Y, Hope BT (2014) Role of nucleus accumbens shell neuronal ensembles in contextinduced reinstatement of cocaine-seeking. J Neurosci 34:7437-7446.

Cruz FC, Javier Rubio F, Hope BT (2015) Using c-fos to study neuronal ensembles in corticostriatal circuitry of addiction. Brain Res 1628:157173.

Davis WM, Smith SG (1976) Role of conditioned reinforcers in the initiation, maintenance and extinction of drug-seeking behavior. Pavlov J Biol Sci 11:222-236.

de Wit H, Stewart J (1981) Reinstatement of cocaine-reinforced responding in the rat. Psychopharmacology 75:134-143.

Fanous S, Goldart EM, Theberge FR, Bossert JM, Shaham Y, Hope BT (2012) 
Role of orbitofrontal cortex neuronal ensembles in the expression of incubation of heroin craving. J Neurosci 32:11600-11609.

Floresco SB (2013) Prefrontal dopamine and behavioral flexibility: shifting from an "inverted-U" toward a family of functions. Front Neurosci 7:62.

Garner AR, Rowland DC, Hwang SY, Baumgaertel K, Roth BL, Kentros C, Mayford M (2012) Generation of a synthetic memory trace. Science 335:1513-1516.

Geisler S, Derst C, Veh RW, Zahm DS (2007) Glutamatergic afferents of the ventral tegmental area in the rat. J Neurosci 27:5730-5743.

Gutman AL, Ewald VA, Cosme CV, Worth WR, LaLumiere RT (2017) The infralimbic and prelimbic cortices contribute to the inhibitory control of cocaine-seeking behavior during a discriminative stimulus task in rats. Addict Biol 22:1719-1730.

Hamlin AS, Newby J, McNally GP (2007) The neural correlates and role of D1 dopamine receptors in renewal of extinguished alcohol-seeking. Neuroscience 146:525-536.

Hebb DO (1949) The organization of behavior. New York: Wiley.

James MH, McGlinchey EM, Vattikonda A, Mahler SV, Aston-Jones G (2018) Cued reinstatement of cocaine but not sucrose seeking is dependent on dopamine signaling in prelimbic cortex and is associated with recruitment of prelimbic neurons that project to contralateral nucleus accumbens core. Int J Neuropsychopharmacol 21:89-94.

Jin J, Maren S (2015) Fear renewal preferentially activates ventral hippocampal neurons projecting to both amygdala and prefrontal cortex in rats. Sci Rep 5:8388.

Jonkman S, Mar AC, Dickinson A, Robbins TW, Everitt BJ (2009) The rat prelimbic cortex mediates inhibitory response control but not the consolidation of instrumental learning. Behav Neurosci 123:875-885.

Kalivas PW, Volkow ND (2005) The neural basis of addiction: a pathology of motivation and choice. Am J Psychiatry 162:1403-1413.

Khoo SY, Gibson GD, Prasad AA, McNally GP (2017) How contexts promote and prevent relapse to drug seeking. Genes Brain Behav 16:185-204.

Koya E, Golden SA, Harvey BK, Guez-Barber DH, Berkow A, Simmons DE, Bossert JM, Nair SG, Uejima JL, Marin MT, Mitchell TB, Farquhar D, Ghosh SC, Mattson BJ, Hope BT (2009a) Targeted disruption of cocaine-activated nucleus accumbens neurons prevents context-specific sensitization. Nat Neurosci 12:1069-1073.

Koya E, Uejima JL, Wihbey KA, Bossert JM, Hope BT, Shaham Y (2009b) Role of ventral medial prefrontal cortex in incubation of cocaine craving. Neuropharmacology 56:177-185.

LaLumiere RT, Niehoff KE, Kalivas PW (2010) The infralimbic cortex regulates the consolidation of extinction after cocaine self-administration. Learn Mem 17:168-175.

Li X, Rubio FJ, Zeric T, Bossert JM, Kambhampati S, Cates HM, Kennedy PJ, Liu QR, Cimbro R, Hope BT, Nestler EJ, Shaham Y (2015) Incubation of methamphetamine craving is associated with selective increases in expression of $B d n f$ and Trkb, glutamate receptors, and epigenetic enzymes in cue-activated fos-expressing dorsal striatal neurons. J Neurosci 35:82328244.

Ma YY, Lee BR, Wang X, Guo C, Liu L, Cui R, Lan Y, Balcita-Pedicino JJ, Wolf ME, Sesack SR, Shaham Y, Schlüter OM, Huang YH, Dong Y (2014) Bidirectional modulation of incubation of cocaine craving by silent synapse-based remodeling of prefrontal cortex to accumbens projections. Neuron 83:1453-1467.

Marchant NJ, Kaganovsky K, Shaham Y, Bossert JM (2015) Role of corticostriatal circuits in context-induced reinstatement of drug seeking. Brain Res 1628:219-232.

Marchant NJ, Campbell EJ, Whitaker LR, Harvey BK, Kaganovsky K, Adhikary S, Hope BT, Heins RC, Prisinzano TE, Vardy E, Bonci A, Bossert JM, Shaham Y (2016) Role of ventral subiculum in context-induced relapse to alcohol seeking after punishment-imposed abstinence. J Neurosci 36:3281-3294.

McFarland K, Kalivas PW (2001) The circuitry mediating cocaine-induced reinstatement of drug-seeking behavior. J Neurosci 21:8655-8663.

McGlinchey EM, James MH, Mahler SV, Pantazis C, Aston-Jones G (2016) Prelimbic to accumbens core pathway is recruited in a dopaminedependent manner to drive cued reinstatement of cocaine seeking. J Neurosci 36:8700-8711.

McNally GP (2014) Extinction of drug seeking: neural circuits and approaches to augmentation. Neuropharmacology 76:528-532.
Meister B (2007) Neurotransmitters in key neurons of the hypothalamus that regulate feeding behavior and body weight. Physiol Behav 92:263-271.

Moorman DE, James MH, McGlinchey EM, Aston-Jones G (2015) Differential roles of medial prefrontal subregions in the regulation of drug seeking. Brain Res 1628:130-146.

Nair SG, Navarre BM, Cifani C, Pickens CL, Bossert JM, Shaham Y (2011) Role of dorsal medial prefrontal cortex dopamine D1-family receptors in relapse to high-fat food seeking induced by the anxiogenic drug yohimbine. Neuropsychopharmacology 36:497-510.

O’Brien CP, Childress AR, McLellan AT, Ehrman R (1992) Classical conditioning in drug-dependent humans. Ann N Y Acad Sci 654:400-415.

Peters J, De Vries TJ (2013) D-cycloserine administered directly to infralimbic medial prefrontal cortex enhances extinction memory in sucroseseeking animals. Neuroscience 230:24-30.

Peters J, LaLumiere RT, Kalivas PW (2008a) Infralimbic prefrontal cortex is responsible for inhibiting cocaine seeking in extinguished rats. J Neurosci 28:6046-6053.

Peters J, Vallone J, Laurendi K, Kalivas PW (2008b) Opposing roles for the ventral prefrontal cortex and the basolateral amygdala on the spontaneous recovery of cocaine-seeking in rats. Psychopharmacology 197:319326.

Peters J, Kalivas PW, Quirk GJ (2009) Extinction circuits for fear and addiction overlap in prefrontal cortex. Learn Mem 16:279-288.

Phillips AG, Vacca G, Ahn S (2008) A top-down perspective on dopamine, motivation and memory. Pharmacol Biochem Behav 90:236-249.

Rhodes SE, Killcross AS (2007) Lesions of rat infralimbic cortex enhance renewal of extinguished appetitive Pavlovian responding. Eur J Neurosci 25:2498-2503.

Rhodes SE, Killcross S (2004) Lesions of rat infralimbic cortex enhance recovery and reinstatement of an appetitive Pavlovian response. Learn Mem 11:611-616.

Rubio FJ, Liu QR, Li X, Cruz FC, Leão RM, Warren BL, Kambhampati S, Babin KR, McPherson KB, Cimbro R, Bossert JM, Shaham Y, Hope BT (2015) Context-induced reinstatement of methamphetamine seeking is associated with unique molecular alterations in Fos-expressing dorsolateral striatum neurons. J Neurosci 35:5625-5639.

Shaham Y, Adamson LK, Grocki S, Corrigall WA (1997) Reinstatement and spontaneous recovery of nicotine seeking in rats. Psychopharmacology 130:396-403.

Siegel S (1999) Drug anticipation and drug addiction: the 1998 H. David Archibald lecture. Addiction 94:1113-1124.

Stefanik MT, Moussawi K, Kupchik YM, Smith KC, Miller RL, Huff ML, Deisseroth K, Kalivas PW, LaLumiere RT (2013) Optogenetic inhibition of cocaine seeking in rats. Addict Biol 18:50-53.

Stewart J, de Wit H, Eikelboom R (1984) Role of unconditioned and conditioned drug effects in the self-administration of opiates and stimulants. Psychol Rev 91:251-268.

Suto N, Laque A, De Ness GL, Wagner GE, Watry D, Kerr T, Koya E, Mayford MR, Hope BT, Weiss F (2016) Distinct memory engrams in the infralimbic cortex of rats control opposing environmental actions on a learned behavior. eLife 5:e21920.

Venniro M, Caprioli D, Shaham Y (2016) Animal models of drug relapse and craving: from drug priming-induced reinstatement to incubation of craving after voluntary abstinence. Prog Brain Res 224:25-52.

Venniro M, Caprioli D, Zhang M, Whitaker LR, Zhang S, Warren BL, Cifani C, Marchant NJ, Yizhar O, Bossert JM, Chiamulera C, Morales M, Shaham Y (2017) The anterior insular cortex $\rightarrow$ central amygdala glutamatergic pathway is critical to relapse after contingency management. Neuron 96:414-427.e8.

Warren BL, Mendoza MP, Cruz FC, Leao RM, Caprioli D, Rubio FJ, Whitaker LR, McPherson KB, Bossert JM, Shaham Y, Hope BT (2016) Distinct Fos-expressing neuronal ensembles in the ventromedial prefrontal cortex mediate food reward and extinction memories. J Neurosci 36:6691-6703.

Warren BL, Suto N, Hope BT (2017) Mechanistic resolution required to mediate operant learned behaviors: insights from neuronal ensemblespecific inactivation. Front Neural Circuits 11:28.

Wikler A (1973) Dynamics of drug dependence. implications of a conditioning theory for research and treatment. Arch Gen Psychiatry 28:611616. 